\title{
WestVirginiaUniversity
}

THE RESEARCH REPOSITORY @ WVU

Graduate Theses, Dissertations, and Problem Reports

2012

\section{Three Essays on the Political Economy of Public Finance}

Adam J. Hoffer

West Virginia University

Follow this and additional works at: https://researchrepository.wvu.edu/etd

\section{Recommended Citation}

Hoffer, Adam J., "Three Essays on the Political Economy of Public Finance" (2012). Graduate Theses, Dissertations, and Problem Reports. 4866.

https://researchrepository.wvu.edu/etd/4866

This Dissertation is protected by copyright and/or related rights. It has been brought to you by the The Research Repository @ WVU with permission from the rights-holder(s). You are free to use this Dissertation in any way that is permitted by the copyright and related rights legislation that applies to your use. For other uses you must obtain permission from the rights-holder(s) directly, unless additional rights are indicated by a Creative Commons license in the record and/ or on the work itself. This Dissertation has been accepted for inclusion in WVU Graduate Theses, Dissertations, and Problem Reports collection by an authorized administrator of The Research Repository @ WVU.

For more information, please contact researchrepository@mail.wvu.edu. 
Three Essays on the Political Economy of Public Finance

Adam J. Hoffer

Dissertation submitted to the College of Human Resources and Education at West Virginia University in partial fulfillment of the requirements for the degree of

\title{
Doctor of Philosophy \\ in Economics
}

\author{
Santiago Pinto, Ph.D., Chair \\ George Hammond, Ph.D. \\ Amanda Ross, Ph.D. \\ William Shughart, Ph.D. \\ Russell Sobel, Ph.D. \\ Department of Economics
}

\section{Morgantown, West Virginia 2012}

Keywords: political economy, special interest groups, spatial econometrics, spillover effects

Copyright 2012 Adam J. Hoffer 


\title{
Abstract \\ Three Essays on the Political Economy of Public Finance
}

\author{
Adam J. Hoffer
}

This dissertation consists of three essays which examine the role political economy factors play in influencing state-level public finance in the United States. In Chapter 1, I introduce the economic logic explaining why political economy factors affect public finance. I then give a brief summary of the three essays presented in Chapters 2-4. Chapter 2 investigates the role tobacco special-interest groups, state ideology, and a number of public finance variables play in determining the state cigarette tax rate. Chapter 3 introduces a new methodology, using spatial econometrics, to investigate tax competition in cigarette tax rates. Chapter 4 examines the disparity in tobacco control spending, specifically investigating states with strong tobacco special-interests. 


\section{Acknowledgements}

First and foremost, I would like to thank my parents, Anita and Brian Little, for their unwavering support. After 21 consecutive years of school, there is almost no one that is as happy to see me finally graduate! They were always there, no matter what I needed, and to them, I cannot say thank you enough.

Academically, I have had tremendous help along the way from many people. My committee; Santiago Pinto, Russ Sobel, Amanda Ross, George Hammond, and Bill Shughart, were very encouraging and ultimately helped shape this dissertation into what it has become. Adam Pellillo was also instrumental in providing advice and feedback on my work and has been a great coauthor that I look forward to working with for several years in the future. I am additionally appreciative to so many other graduate students, professors, faculty, conference participants, and colleagues who provided invaluable inspiration and assistance along the way.

Finally, to my remaining friends and family, I just want to express my gratitude. I feel exceptionally lucky and grateful for the people who are such a huge part of my life. It has been a long journey to this point in my life and career, but my friends and family supported me each step of the way. 


\section{Table of Contents}

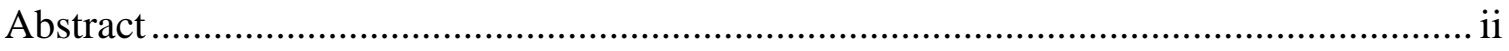

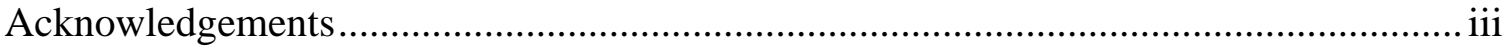

List of Figures ...................................................................................................... vi

List of Tables ...................................................................................................... vii

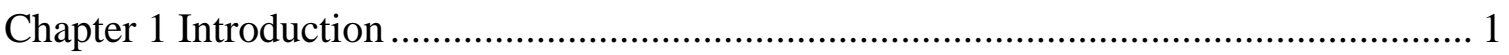

1.1 The Political Economy of Tobacco Excise Taxation.................................................. 2

1.2 Reevaluating Cigarette Tax Competition.................................................................. 3

1.3 Special Interest Group Impact on Tobacco Control Spending ………………......... 4

Chapter 2 The Political Economy of Cigarette Taxation..................................................... 6

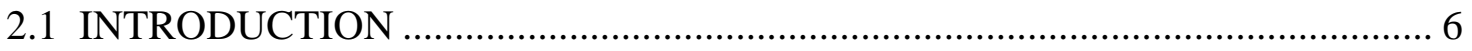

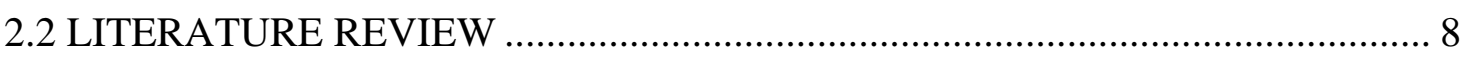

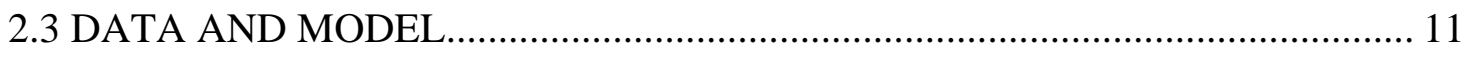

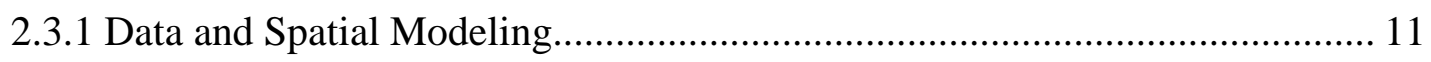

2.3.2 Coefficient Predictions.................................................................................. 14

2.3.3 Changes Over Time .................................................................................. 15

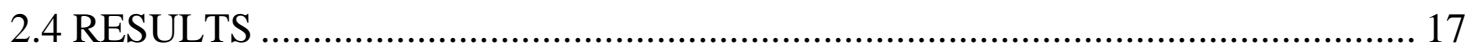

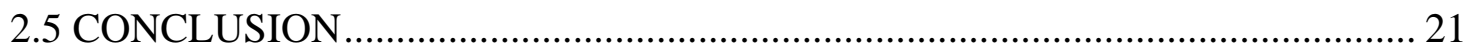

2.6 APPENDIX

Chapter 3 Reevaluating Horizontal Tax Competition ........................................................ 33

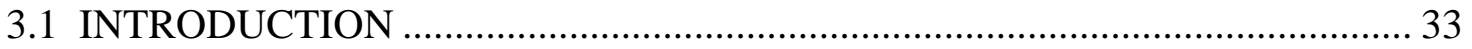

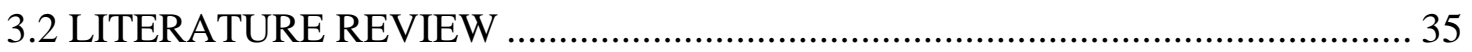

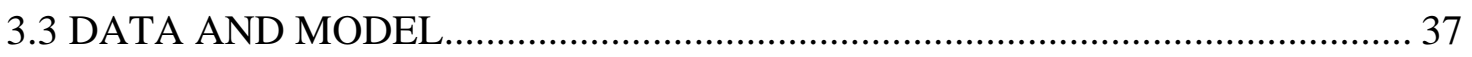

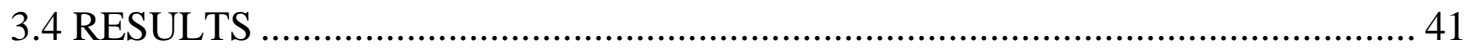

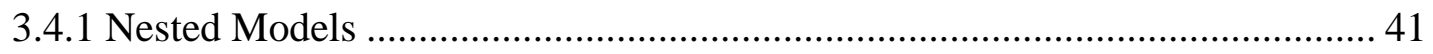

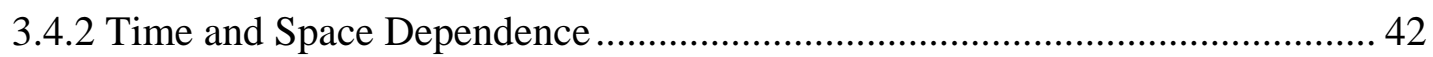

3.4.3 Space-Time Direct, Indirect, and Total Effects ............................................... 43

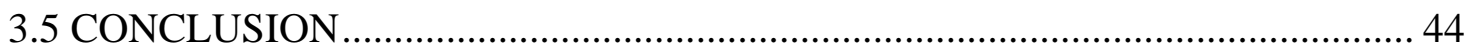

Chapter 4 Special Interest Group Influence on Tobacco Control Spending ${ }^{*}$..................... 61

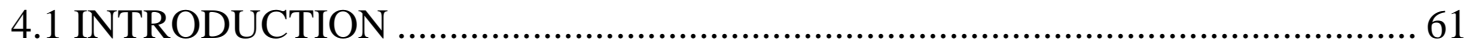

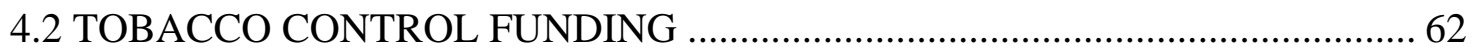

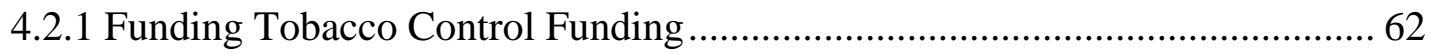

4.2.2 State Spending on Tobacco Control .............................................................. 62

4.2.3 Outcomes of Tobacco Control Spending.......................................................... 63 
4.3 SPECIAL INTEREST GROUPS AND TOBACCO CONTROL FUNDING ....... 65

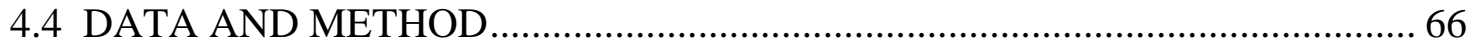

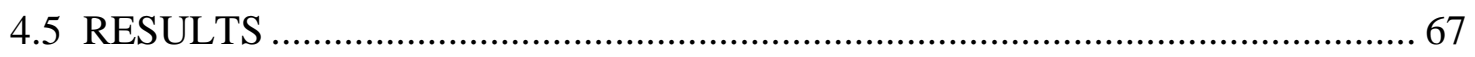

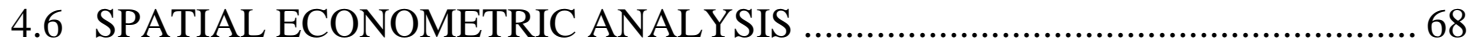

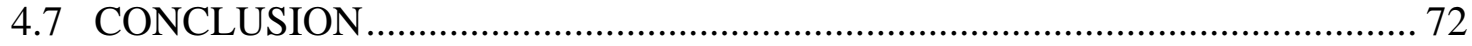

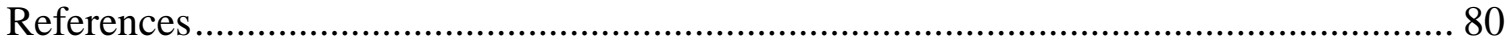




\section{List of Figures}

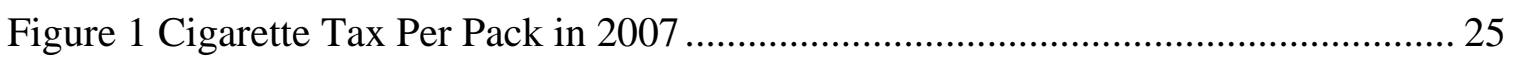

Figure 2 Pounds of Tobacco Produced by State in 2007 ............................................. 25

Figure 3 Between State Variance of Cigarette Tax Rates.............................................. 26

Figure 4 State Tobacco Control Spending (2007 Dollars Per Capita) and State Tobacco

Production (Pounds of Tobacco) in 2007, Respectively.................................. 73 


\section{List of Tables}

Table 1 Descriptive Statistics and LM Test Results ................................................... 26

Table 2 Determinants of State Cigarette Tax Rates.................................................... 27

Table 3 Determinants of State Cigarette Tax Rates with Alternative SpecialInterest Measure ................................................................................... 28

Table 4 SDM Using Restricted Time Period Data........................................................ 29

Table 5 Public Finance Variables Alternative Model Specification Robustness Checks. 30

Table 6 Correlation Matrix of the SDM Specification used in Table 2........................... 31

Table 7 Within State Analysis Using Spatial Durbin Model Specifications .................... 32

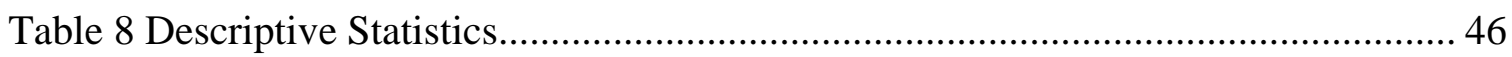

Table 9 OLS and SDM Replications of Previous Model Specifications Used in the

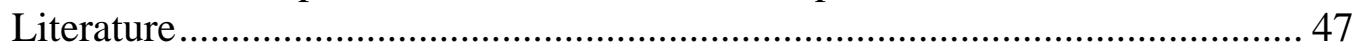

Table 10 Space-Time Estimations of U.S. State Cigarette Tax Rates ............................ 48

Table 11 Space-Time Direct Effect Estimates............................................................ 49

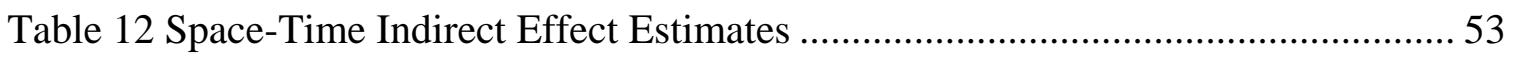

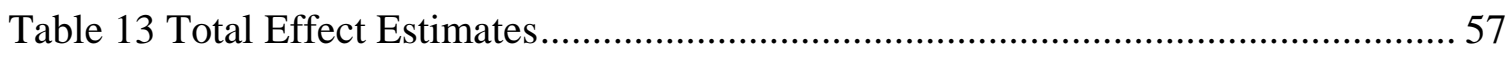

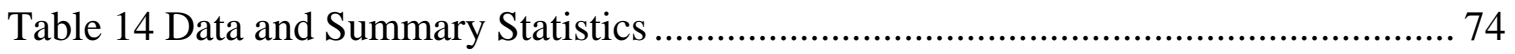

Table 15 OLS Results for Tobacco Production ........................................................... 75

Table 16 OLS Results for Tobacco Producer ............................................................... 76

Table 17 OLS Results for State Lobbying Expenditures............................................. 77

Table 18 Model Specification Results ........................................................................ 78

Table 19 Spatial Econometric Results for Tobacco Production .................................... 79 


\section{Chapter 1 Introduction}

For most of its existence as a field of economic study, public finance was dominated by mathematical calculations that excluded any measure of the political environment. Indeed, even in modern public finance textbooks, discussion of public choice topics remains confined to chapter one (Holcombe 1998). However, the political environment is a key component in the design and functioning of the public finance system, in particular, the tax system.

Specifically, the efficiency of the public finance system can be altered substantially if the political costs of taxation are considered. Holcombe (1998) notes that the more transparent costs of administration (enforcing the laws and collecting the taxes) and compliance (taxpayers calculating and paying their taxes) are non-trivial, but have been recognized for years. It is the less recognized political costs of taxation that have been growing in size, yet have remained somewhat unnoticed. Most important of those political costs are costs associated with rent seeking from those who wish influence tax policy.

Holcombe (1998) summarizes the issue of political costs in a fiscal structure that is exemplified by the system currently in place in the United States, "A tax structure that is easily modified can bring with it substantial political costs, not only because people have an incentive to lobby for changes for their benefit, but also because they must be on their guard to protect themselves from changes that could harm them. These political costs have largely been ignored by economists who have analyzed the efficiency of the tax system.” 
The aim of this dissertation is to contribute to the literature that illustrates the role political economy factors play in influencing public finance. Specifically, I focus on the role that the tobacco industry plays in affecting cigarette tax rates and tobacco control spending. I also focus on the role of spatial connectivity in policy setting. This allows me to examine spatial 'spillover' effects from multiple political economy factors as well as competition between multiple governments over a similar tax base.

\subsection{The Political Economy of Tobacco Excise Taxation}

The vast literature relative to the tobacco industry has focused on the consumption of cigarettes and tobacco, elasticities of demand, and the addictive nature of cigarettes, as shown by the 45-study meta-analysis by Andrews and Frank (1991) and the 87-study meta-analysis by Gallett and List (2002). Relatively few studies have investigated the determinants of the tax, rather than the results from the tax.

This paper helps fill that under-researched side of cigarette taxation. I investigate the role of political economy factors, specifically tobacco special-interest groups, in influencing state-level cigarette tax rates both within a state and in neighboring states (spillover effect) using a spatial econometric framework. I also use an expanded data set including more recent data to examine time subsets of the data.

I find that tobacco production in a state is associated with a significantly lower tax rate. This finding similarly held for the use of campaign contributions from the tobacco industry to measure tobacco special-interest. The tobacco special-interest effect is shown to influence neighboring states as well. Because states compete over a tax base through their tax rate, if a special interest group is able to "buy" a lower tax rate in one state, neighboring states that are competing with that state will be affected as well. 
Therefore, the standard ordinary least squares (OLS) models substantially underestimate the total effect of special interest groups in influencing policy. Because of the interdependent nature of tax rates and spatially correlated independent variables, such as tobacco special interest group locations, a spatial Durbin model (SDM) is necessary to account for all of these factors. Indeed, when comparing the SDM and OLS coefficients, the SDM reports a coefficient six times as large as the OLS model.

When periods of the data are examined, stark differences in the determinants of cigarette tax rates emerge. As the variance between state tax rates has changed over time, so has the relative interdependence among states. Also, the coefficients on the most recent data revealed an opposite sign for many the variables when compared to earlier periods.

\subsection{Reevaluating Cigarette Tax Competition}

A recent development in the economics literature has been the analysis of tax rate competition. Tax competition between neighboring states is denoted as horizontal competition and tax competition between states and the federal government is denoted as vertical competition. These multiple governments are often viewed as competitors over the same tax base. For this reason, states may choose to set and adjust their tax rates, strategically, according to the actions of their competitors.

This essay presents a new methodology for empirically estimating the horizontal tax reaction function, using the most recent spatial econometric techniques. This enables a more complete understanding of tax competition and geographical similarities in state excise tax rates and therefore a more accurate estimation of simultaneous horizontal and vertical tax competition. 
Empirically, I use a 48-year panel data model, incorporating space-time dynamics as suggested by Debrasy et al. (2011). By using this model, I estimate the space-time direct effect (persistence) and the space-time indirect effect (horizontal competition). I find that there is no significant evidence of a vertical tax competition from states and a negative horizontal response, suggesting states will lower their tax rate (or increase by a smaller amount than it would have otherwise) in response to a neighboring state increasing its tax rate.

I compare and contrast this result to previous findings in the literature, which suggest a positive horizontal reaction function. I do so by successfully replicating previous results using existing model specifications, which generate an upwardly biased horizontal reaction function.

\subsection{Special Interest Group Impact on Tobacco Control Spending}

While a large literature examines the impact of tobacco control programs and policies on tobacco use, only a handful of studies have addressed the causes of cross-state variation in tobacco control funding. This may be surprising, as the effects of tobacco control programs are studied by scholars in many disciplines, including economics, the health sciences, and political sciences, as well as by practitioners in public health organizations. Therefore, this essay fills a void in the literature by investigating the source of the discrepancy seen in funding for these programs.

This paper, based on Hoffer and Pellillo (2012), begins by considering political economy factors that may influence tobacco control spending. I focus specifically on the role played by tobacco special-interest groups. Tennessee, a major tobacco producer, had the lowest level of expenditures on tobacco control in 2007, with $\$ 0.13$ in tobacco control 
funding per person; while the top ten states in terms of tobacco control funding, produce no tobacco at all.

I use an eight-year panel to examine, econometrically, the relationship between the political economy factors and tobacco control spending. The panel years were chosen so that state revenue from the 1998 Master Settlement Agreement (MSA), usually earmarked for spending on tobacco control, could be incorporated into the analysis.

My results show that tobacco special-interest influence is negatively correlated with tobacco control spending. Areas with strong tobacco special-interests do not want higher levels of tobacco control spending, as that spending is aimed at decreasing the consumption of the industry's product. States that received more MSA revenue, tobacco excise tax revenue, and whose citizens were more liberal politically (in the modern sense) all had greater levels of tobacco control spending per capita. 


\section{Chapter 2}

\section{The Political Economy of Cigarette Taxation}

\subsection{INTRODUCTION}

Government spending has skyrocketed over the past half-decade, both at the federal level and the state level. To fuel this spending, governments have turned to a variety of revenue sources. A popular option has been to increase excise taxes, particularly the tax rate on cigarettes. Because cigarette taxes serve as a 'sin' tax and the demand for cigarettes is highly price inelastic, policy makers face a favorable situation. They have the ability to increase taxes on a specific good, consumed minority of the population, without drastically shrinking the tax base, and consequently increase their short-run tax revenues without facing major political pushback from voters. Seizing this opportunity, policy makers have exploited the cigarette excise tax rate heavily in recent years. The average combined state and federal tax rate per pack of cigarettes grew from 39.2 cents in 1990 to 75.96 cents in 2000 and increased to 146.25 cents in 2007. ${ }^{1}$ Farrelly, Nimsch, and James (2003) examine 36 increases in state-levied cigarette taxes between 1989 and 2000. The average one-year increase in revenue from these hikes was more than $\$ 83.6$ million.

While state politicians may not experience large voter-driven resistance to cigarette tax hikes, strong resistance may come from tobacco special interest groups. The role of special interest groups in influencing political outcomes has been well documented (Kreuger, 1974; Tullock, 1967; Becker, 1983), however, the relative influence and effectiveness that interest groups have on various aspects of the political process still remains a topic for debate. Recent studies have explored the impact of tobacco special interest groups on policy outcomes (Hoffer

\footnotetext{
${ }^{1}$ Data from Orzehowski and Walker (2007)
} 
and Pellillo, 2012; Fredrickson and Mamun, 2008; Devereux, Lockwood, and Redoano, 2007; and Holcombe, 1998). This study moves the literature forward by merging the established special interest group research with the relatively new field of spatial econometrics.

Spatial econometric techniques allow regression models to include measures of spatial interaction (spatial autocorrelation) and estimate the degree of spatial interaction among spatially interdependent units. Spatial techniques are of particular applicable in the area of policy analysis, as regions often choose their policies with consideration of the policies of neighboring regions. This is especially true in the case of tax policy, as competition for mobile tax bases incentivizes policy makers to carefully monitor the policies of their competitors while choosing their own tax policies.

Spatial techniques also allow for analysis of spatial spillover effects, in which a change in a variable influencing a region's policy also impacts neighboring regions' policies due to the spatially interdependent aspect of policy decisions. This means that tobacco special interest groups may exhibit influence over a much broader area than previously estimated. For example, if tobacco special interest groups, concentrated in a state, are able to influence policy makers in that state to set lower excise taxes on cigarettes, then politicians in neighboring states, out of fear of losing their mobile tax base due to cross-border shopping, may set lower taxes in their state as well. This paper attempts to quantify the spatial spillover of special interest groups and measure the degree of their spatial influence.

Then, this paper explores a substantial change in the spatial interaction among states over time. States have widely differed in their willingness to use excise taxes to raises their growing need for additional revenue, causing the variance in cigarette tax rates across states to grow 
exponentially in recent years. Therefore, this paper incorporates more recent data and time splits of the data to illustrate these changes over time.

\subsection{LITERATURE REVIEW}

The vast literature relating to the tobacco industry has primarily focused on the consumption side, summarized in the 45-study meta-analysis on cigarette consumption by Andrews and Frank (1991), the addictive nature of cigarettes and other tobacco products (Becker, Grossman, and Murphy, 1994; Becker and Murphy, 1988; Chaloupka, 1991; and Gruber and Koszegi, 2001, 2002, 2004), and specifically centered on estimating elasticities of demand, as exemplified by the 87-study meta-analysis by Gallett and List (2002). There has also been a growing literature on the price effects of cigarettes and tobacco, centered on non-market, government-imposed taxes which focus on revenue raising and market responses to the tax (Nelson, 2002; Farelly, Nimsch, and James, 2003; and Emery et al., 2002).

Because the demand for cigarettes is highly inelastic, efficiency arguments can also be made for the selective excise taxes. The inverse elasticity rule of commodity taxation suggests that in order to minimize the deadweight loss created by taxation, goods should be taxed according to their inverse elasticity of demand. This would suggest good like cigarettes should have a higher tax because, when needing to raise revenue, the government can mitigate the market distortion by taxing goods with highly inelastic demand curves more heavily. Curiously, however, there is not a tax on inelastic goods such as medicine and prescriptions.

Converse to the inverse elasticity argument, Holcomb (1998) suggests that, from a public choice perspective, the most desirable tax rate would be a flat tax on income and commodities. Because relative tax rates are variable by government politicians, industries facing a tax on their goods would engage in directly non-productive activities, such as lobbying the government for 
preferential treatment. Once the social welfare loss is taken into consideration, the least distortive tax rate structure might be a flat tax system.

Relatively few studies have investigated an alternative approach to the issue, which involves moving the tax to the left-hand side of the regression to examine the determinants of the tax, rather than the results from the tax. This relatively small literature permits room for further investigation. Devereux, Lockwood, and Redoano (2007), Fredrickson and Mamun (2008), Holcombe (1997), and Besley and Rosen (1998) all use cigarette excise taxes as the dependent variable, but the focus of these articles is wide-ranging.

Holcombe (1997) is the first study to specifically analyze tobacco industry’s ability to influence state-level cigarette tax rates. He uses cross sectional data from 1985 and 1991. To show the effect of special interest groups, Holcombe includes a variable measuring number of acres per capita of tobacco farms within a state and finds a significantly negative relationship between the tax on cigarettes and acres per capita. Holcombe concludes that the taxes levied on tobacco are not directly correlated with other excise taxes, but rather are heavily influenced by special interest groups.

Besley and Rosen (1998) provide the seminal paper combining empirical cigarette taxation and vertical tax competition between the federal and state governments using panel data spanning 1975-1989. They find a positive reaction response from state to an increase in the federal tax. Neither the tobacco industry's share of state income nor the state gasoline tax had a statistically significant coefficient.

Fredrickson and Mamun (2008) provide the most complete analysis of the factors affecting cigarette taxes thus far, using a 1975-2001 panel. Estimating a multitude of model specifications, they focus on the negative reaction of states (decreasing their tax rate) in response 
to increases of the federal cigarette tax. They also find tobacco income positive and significant in a majority of specifications, all including state fixed effects. Devereux, Lockwood, and Redoano (2007) similarly focus on tax competition. Depending on the model specification, the sign on state tobacco industry size was shown to be positive or negative. Most of the political variables were insignificant in a majority of model specifications.

Overall, a few studies have found that states with strong interest in tobacco have lower tax rates, while other studies have suggested that tax rates are spatially correlated, but these individual results require additional evidence and explanation. No study thus far has combined a spatial model with an investigation of the special-interest effect to provide evidence of spillover effects from such groups.

These spatial effects can be substantial. A number of studies have investigated policy changes and the resulting interstate effects due to changes in consumer behavior. A popular topic of investigation has been changes in lottery revenues from the introduction of new lottery or gambling activities in neighboring states or counties. Tosun and Skidmore (2004) use annual lottery sales for West Virginia counties from 1987 to 2000 to investigate the introduction of lottery games in states bordering West Virginia. They find that lottery revenues significantly declined in counties that border states who introduced new lottery games. Similarly, Garrett and Marsh (2002) compare lottery sales in border and nonborder counties in Kansas. They find, similar to Tosun and Skidmore (2004), that Kansas counties which border states with lotteries tend to have lower sales.

State policy selection and policy changes have ramifications of millions of dollars annually to state budgets. Policy makers are highly aware of the mobility of their tax bases and 
select policies after taking into consideration the policies of their neighbors. Therefore, it is essential to include this spatial aspect of policy when conducting any sort of empirical analysis.

\subsection{DATA AND MODEL}

\subsubsection{Data and Spatial Modeling}

Using U.S. state-level data from 1960-2007 on all 50 states plus Washington, D.C., this paper begins by investigating the presence of geographical similarities in cigarette tax rates across states. LeSage and Pace (2009) describe how model misspecification arising from ignoring spatial correlation in the dependent variable creates omitted variable bias and inefficiency. To ensure spatial correlation is properly accounted for, the data are analyzed following the procedure outlined by Florax, Folmer, and Rey (2003) using Lagrange Multiplier (LM) tests designed by Anselin, Bera, Floraz, and Yoon (1996). Table 1 shows the results of these tests for the regression model presented in Table 2. ${ }^{2}$ Because the LM Lag Robust test produces a significant coefficient and the LM Error Robust test does not, a model including a spatial autoregressive term (in the dependent variable) was revealed to be the appropriate model choice. This implies state cigarette tax rates are indeed spatially correlated. Figure 1 further highlights the geographical similarities for a single year of the data.

A spatial autoregressive model (SAR) includes spatially weighted values of the dependent variable within the conventional regression structure. The spatial Durbin model (SDM) builds upon the SAR by additionally including spatially weighted values of the independent variables. Following LeSage and Pace (2009), the SDM model was chosen as the

\footnotetext{
${ }^{2}$ The first two tests, LM Lag and LM Error, test for the existence of spatial correlation in the dependent variable and the error term, respectively. If both tests are significantly different from zero, the second set of LM tests, LM Lag Robust and LM Error Robust, test for the existence of spatial correlation, similar to first stage tests, but account for the existence of spatial correlation in the alternative location (error term or dependent variable). Table 1 reports the LM test results for the regression using only the 2000-2007 data. The LM test results for the other regressions presented in the paper are available upon request.
} 
appropriate model because the SAR model is nested in the SDM and the SDM has the ability to absorb spatial error of omitted variables which are correlated with the spatially weighted independent variables. The panel fixed effects SDM model is represented as follows ${ }^{3}$

(1) $\mathrm{Y}_{\mathrm{S}, \mathrm{t}}=\rho \mathrm{W} \mathrm{Y}_{\mathrm{S}, \mathrm{t}}+\alpha_{\mathrm{S}, \mathrm{t}}+\beta \mathrm{X}_{\mathrm{S}, \mathrm{t}-1}+\mathrm{W} \theta \mathrm{X}_{\mathrm{S}, \mathrm{t}-1}+\varepsilon_{\mathrm{S}, \mathrm{t}}$, where $\varepsilon_{\mathrm{S}} \sim\left(0, \sigma^{2} \mathrm{I}_{\mathrm{n}}\right)$.

Solving for $Y$ and setting $A=\left(I_{s}-\rho W\right)^{-1}$ yields the regression model,

(2) $\mathrm{Y}_{\mathrm{S}, \mathrm{t}}=\mathrm{A}\left[\alpha_{\mathrm{S}, \mathrm{t}}+\beta \mathrm{X}_{\mathrm{S}, \mathrm{t}-1}+\mathrm{W} \theta \mathrm{X}_{\mathrm{S}, \mathrm{t}-1}+\varepsilon_{\mathrm{S}, \mathrm{t}}\right]$,

where $Y$ is the state excise tax per pack of cigarettes (in cents) in state s and time t; $\rho$ is a scalar parameter that describes the magnitude of the spatial interaction; $\mathrm{W}$ is a contiguity-based spatial weight matrix; $\alpha$ represents the fixed effects, $\beta$ is a vector of coefficients on $\mathrm{X}$, the matrix of independent variables including: pounds, the number of pounds of tobacco the state produced (in millions); lobby, campaign contributions (in thousands of dollars) from the tobacco industry to politicians running for state offices, averaged over the election cycle; nominate, a NOMINATE measure of state ideology (Berry et al. 2010); citizen, a citizen ideology (liberalism) indicator (Berry et al. 1998); gini, the gini coefficient of a state, measuring income inequality (out of 100); debt, the per capita amount of state expenditures used to pay interest on debt; healthcare, the per capita dollar amount of state public expenditures on health and hospitals (in thousands of dollars); sales tax, the state sales tax rate; no income tax, a dummy variable equal to one for states that charge no income tax to their residents; under 15, the percentage of a state's population under the age of 15 ; over 65 , the percentage of a state's population over the age of 65 ; white, the percentage of a state's population that is Caucasian; urban, the percentage of a state's population that is listed a living in an urban area; educ, the percentage of the state population having at least

\footnotetext{
${ }^{3}$ The random effects model is: $\mathrm{Y}_{\mathrm{S}, \mathrm{t}}=\mathrm{A}\left[\beta \mathrm{X}_{\mathrm{S}, \mathrm{t}-1}+\mathrm{W} \theta \mathrm{X}_{\mathrm{S}, \mathrm{t}-1}+\left(\alpha_{\mathrm{S}, \mathrm{t}}+\varepsilon_{\mathrm{S}, \mathrm{t}}\right)\right]$. Haussman test statistics support the use of the fixed effects model and are available upon request.
} 
a Bachelor's degree; ); $\theta$ is the coefficient of the spatially weighted vector of $\mathrm{X}$; and a normally distributed error term $\varepsilon$. Table 1 shows the summary statistics for all variables.

The definition of state neighbors is described by the spatial weight matrix, W. W is exogenously specified in (2) and (3) using a row-stochastic Delaunay contiguity-based spatial matrix. ${ }^{4}$ A contiguity-based weight matrix was selected because states compete for mobile tax bases primarily with their neighbors. Cross-border transactions almost always take place between states that share a border. State politicians also model their policies most closely to their bordering states, knowing that the bulk of any cross-border transactions involved in their state or with their citizens will take place with their bordering states.

The results from spatial models with an autoregressive term can be disaggregated and analyzed by direct effects, indirect effects, and total effects. Direct effects represent the effect that a change in an independent variable has on its own state's dependent variable; indirect effects show the spillover effects on neighboring states; and total effects are the sum of the direct and indirect effects. Note that $\left(\mathrm{I}_{\mathrm{s}}-\rho \mathrm{W}\right)^{-1}$ can be re-written as

$$
\left(\mathrm{I}_{\mathrm{s}}-\rho \mathrm{W}\right)^{-1}=\mathrm{I}_{\mathrm{s}}+\rho \mathrm{W}+\rho^{2} \mathrm{~W}^{2}+\rho^{3} \mathrm{~W}^{3} \cdots
$$

This equation illustrates how the effects of nearby states decay in magnitude with higher order neighbors, with first-order neighbors' (states sharing a border) impact multiplied by $\rho$, second neighbors' (neighbors of the neighbor) impact multiplied by $\rho^{2}$, and so on (LeSage and Dominguez 2010). As shown in (2), (3) is multiplied by $\mathrm{I}_{\mathrm{s}} \beta_{\mathrm{r}}$ (r explanatory variables) to create an $n$ by $n$ matrix of impacts for each independent variable. LeSage and Pace (2009) define the

\footnotetext{
${ }^{4}$ This method uses Delaunay triangles, Voronoi tessellation, derived from state latitude and longitude coordinates). This procedure comes from the Spatial Statsitics Toolbox 2.0 created by R. Kelley Pace: http://www.spatialstatistics.com/software/space_tool_box2/toolbox2_documentation2a.pdf. Cartographic Boundary Files for multiple geographic levels for the creation of weight matrices are available from the Census Bureau at http://www.census.gov/geo/www/cob/bdy_files.html.
} 
average of the sum of the diagonal elements of this $n$ by $n$ matrix as the direct effect and the average of the sum of off-diagonal elements in each row as the indirect effect.

\subsubsection{Coefficient Predictions}

$\rho, \in(-1,1)$, is endogenously determined and posited to be positive significant. A positive $\rho$ implies that states set their tax rates similarly to their neighbors, with a $\rho$ value of one signifying that states perfectly mimic the policy of their neighbors.

If the special interest theory is empirically valid, than states producing larger quantities of tobacco will have lower taxes on cigarettes. Figure 2 shows the amount of tobacco grown in each state. Comparing with Figure 1, Figure 2 helps illustrate the prediction that pounds negatively impact cigarette excise taxes. Figure 2 also demonstrates spatial similarities in an independent variable, providing additional justification for use of a SDM instead of a SAR. State lobby is also expected to have a negative coefficient because larger campaign contributions are expected to influence politicians to set more favorable tax rates for their contributors.

In many industries, it is often the case that businesses can be attracted to areas which grant them political favor, such as a more favorable tax system. This would create an endogineity problem when investigating the direction of causality. In agriculture, however, farmers almost always locate in specific locations and then proceed to attempt to gain political favor. While industries such as manufacturing or textiles can locate their capital almost anywhere, agriculture depends on numerous location-specific attributes, such as soil quality, rainfall, and temperature. ${ }^{5}$

5 Specifically, tobacco is highly sensitive to aeration in soil, preferring soil with good drainage but the capacity to store water for dry spells (Pearce, Bailey, Seebold, and Townsend, 2011). Tobacco also needs an extremely nutrient-rich soil base, frequently requiring large doses of fertilizer and tobacco seeds excel in temperatures of between 70 degrees and 75 degree Fahrenheit, with temperatures of greater than 90 degrees causing uneven germination and predisposing the plants to cold damage; young seedlings often scorch from exposure to temperatures greater than $100^{\circ} \mathrm{F}$ after two hours (Pearce, Denton, Schwab., 2011). 
The ideology measures, estimating the political liberalness of a states' politicians (nominate) and citizens (citizen) are similarly expected to be negative due to the general liberal perception of the proper role of the state in taxation and correcting externalities. State sales tax rates, and no income tax are used to test if revenue-raising purposes are the cause of higher excise taxes on cigarettes. If a positive correlation exists, revenue aims could determine excise tax rates. On the spending side, debt is believed to be positively correlated with cigarette excise taxes as larger debts should drive states to seek additional revenue.

Healthcare spending incorporates factors from state revenue, sin taxes, and special interest groups, which may all contribute to the effect health has on cigarette taxes. The more a state spends on healthcare, the more revenue the state will need, which would imply the need for higher cigarette taxes. Likewise, a portion of the expenses generated from the negative health effects from cigarette consumption is paid for by state governments, driving a demand for higher cigarette taxes. The impact from competing interest groups, as described by Becker (1983), will have a similar effect. While tobacco lobbying totaled \$26.1 million in 2007, the healthcare industry totaled over $\$ 267.1$ million in lobbying during the same year. ${ }^{6}$ This large discrepancy would indicate more favorable results towards the healthcare industry's special interest rather than the tobacco industry's special interest, therefore decreasing the ability of the tobacco industry to obtain preferential tax treatment and resulting in higher taxes. Thus, health is expected to be positively correlated with cigarette taxes.

\subsubsection{Changes Over Time}

This paper also seeks to illustrate that the factors influencing tax policy have changed substantially over time. In order to raise revenue in order to keep pace with skyrocketing levels of spending, debt, and future liabilities, states have been searching for as much revenue as they

\footnotetext{
${ }^{6}$ Data from the Center for Responsive Politics: http://www.opensecrets.org/industries/alphalist.php
} 
can collect. A large number of states have turned to increases in their excise taxes, such as tobacco, as source of additional revenue. Other states, however, have used more broad-based tax increases, such as increases in the sales tax or the income tax, to increase their tax revenue, while making only marginal adjustments to their excise tax rates. This has created an explosion of the variance in the cigarette tax rate seen across the U.S. as time has moved forward. Figure 3 plots the variance of excise taxes, in cents per pack, across all U.S. states and Washington D.C. from 1960 through 2007.

A majority of the empirical studies investigating tobacco taxes use data before 1990, where the variance across states was only slightly above zero. One of the aims of this paper is to incorporate the most recent empirical data into a regression framework, from 2000 to 2007, where the variance was the greatest. Then, this study divides the complete data set, spanning 1960 to 2007, into three additional subgroups: 1960-1983, 1984-2007, and 2000-2007. The year break of 1983 was strategically selected due to the federal government's doubling of the federal cigarette tax rate in 1983 from four cents to eight cents ${ }^{7}$. It was the first increase of the federal excise tax rate on cigarettes since 1952. This prompted a number of state governments to start increasing their own tax rates. The second break of 2000 was selected to allow analysis of the most recent data and to include the two most recent federal cigarette tax increases.

The factors that were influential in the middle part of the century may be substantially less influential in the $21^{\text {st }}$ century. Ideological perspectives of politicians and citizens have changed dramatically in several parts of the country, along with many policies in those areas. Likewise, with the growing need for revenue, states may have changed their reasoning for

\footnotetext{
${ }^{7} 1984$ was the break for columns six and seven because the federal tax is lagged by one year, so the independent variable data is from 1983.
} 
taxation on the spectrum of taxing a "sin good" more towards taxation as a means of revenue creation.

\subsection{RESULTS}

Table 2 presents the results from an OLS, a SAR, and an SDM regression investigating the between state differences, using the full set of explanatory variables and the most recent data from 2000-2007. The pounds variable was negative and significant in all three model specifications, as hypothesized, however the overall magnitude varies substantially by model choice. The OLS regression yields a coefficient of -0.12 , implying that for every million pounds of tobacco that a state grows, it will have a lower cigarette tax rate by 0.12 cents. This magnitude is substantial as many of the tobacco-producing states grew several hundred million pounds of tobacco (e.g. Kentucky grew over 196 million pounds of tobacco in 2007) and state tobacco tax collections totaled more than \$14 billion in 2007.

The OLS results are most comparable to the SAR direct effect estimates. At -0.11 , the direct effect coefficient on pounds from the SAR regression is very similar to the OLS estimate, but the SAR model adds explanatory power to the model by accounting for the spatial correlation in the data. The SAR model estimates the spillover effects resulting from the interdependent policy decisions at the state level. These indirect effects add an additional -0.10 to the total effect, suggesting that the spillover effects from tobacco special interest are almost as influential as the effect of special interest within the state.

The SDM model further improves upon the model specification by including spatially weighted dependent variables to the regression. These variables imply that special interest

groups in a neighboring state, for example, may influence a state's tax rate directly rather than transmitting this impact solely through spatial dependence in cigarette tax rates. Including these 
effects into the regression increases (in absolute value) the direct effect coefficient to -0.18 and yields an indirect effect coefficient of -0.54 , more than five times the indirect coefficient from the SAR regression. The total effect, sum of the direct and indirect effects, of pounds from the SDM regression is six times the size of the OLS estimation and more than five times the size of the SAR regression. This suggests that previous estimates of the effect of special interest groups that have not taken spatial effects fully into consideration may have substantially underestimated their overall effect.

The $\rho$ parameter, measuring the degree of spatial dispersion, was strongly significant and positive for both the SAR and the SDM specifications. This confidently illustrates the need for a spatial autoregressive term, identifying the spatial model specifications as more accurate than OLS. The SAR model yielded a coefficient of 0.50 and the SDM model generated a coefficient of 0.22. The SDM coefficient was expectedly smaller, as the spatially weighted independent variables account for more of the spatial correlation in the SDM regression. These coefficients indicate a strong presence of spatial correlation in cigarette tax rates across states. The spatial correlation does not fall below 0.01 until the seventh neighbor in the SAR regression and the fourth neighbor in the SDM specification.

Analyzing the SDM results, the nominate coefficient was positive and significant for the direct effect estimation, signifying that states whose politicians were more liberal had higher cigarette tax rates. The coefficient on citizen was also positive and statistically significant for the indirect effects and total effects, implying that citizen ideology further to the left will create a higher demand for cigarette tax rates, and that this effect is transmitted primarily through spatial similarities. 
The gini coefficient was negative and significant, indicating that states with more income equality had lower cigarette tax rates. This also means that states with more income inequality had higher cigarette tax rates. Because cigarettes are income inelastic, the burden of taxation on cigarettes generally falls more heavily on the lower income households. This effect is exacerbated by states with more income inequality placing higher taxes on an income inelastic good, cigarettes.

Finally, debt had a positive and significant coefficient, as hypothesized. States that are in worse fiscal trouble, spending more on debt per capita, used higher cigarette tax rates to help generate additional revenue. Healthcare, however, did not have a coefficient statistically different than zero.

Table 3 similarly presents the OLS, SAR, and SDM regressions using the lobby variable as a measurement of state special interest. Again, the $\rho$ parameter was positive and significant for both the SAR and SDM models, indicating the superiority of the spatial model specifications. The $\rho$ parameter was slightly larger for SAR model, 0.52 , and nearly fifty percent larger for the SDM specification, 0.31, than in the Table 2. Even with this increase in magnitude, the effect of the spatial correlation still falls below 0.01 by the fourth neighbor in the SDM model.

The lobby coefficient was negative and significant, for the direct, indirect, and total coefficient estimates in both the SAR and the SDM model. In the SDM model, the indirect coefficient, -3.74 , was more than three times as large as the direct coefficient, highlighting the importance of including the spillover effects into the model. The total coefficient of -4.93 indicates a total effect of holding down cigarette tax rates of 4.93 cents for every thousand dollars spent on campaign contributions to state political campaigns. 
The remainder of the results from Table 3 are analogous to the results in Table 2. Every coefficient maintained the same sign and most coefficients had a marginal change in coefficient magnitude.

Table 4 restricts the data by various years. The first specification used the complete data set, spanning 1960-2007. The next two specifications split the data at 1983, so that the second data split uses data from 1960-1982 and the third data set uses data from 1983-2007. Finally, the fourth split of the data exploits only the most recent data, from 2000-2007.

The $\rho$ parameter varied substantially in magnitude and significance in the various subsets. Over the entire data set, $\rho$ was positive and significant, with a value of 0.57 . This result is driven primarily by the data split from 1982-2007, as the $\rho$ coefficient was substantially smaller for the 1960-1982 data. The $\rho$ parameter was also substantially smaller and not statistically significant for the 2000-2007 data split.

In the total effects, nominate was negative and not statistically different from zero in the pre-1983 split, but was positive and significant in the 1983-2007 split. This suggests that the role of political ideology has played a much larger role since 1983. Conversely, the debt variable was much more influential in the 1960-1983 split than the post 1983 split. This is likely due to the fact that debt levels have outpaced the ability of excise taxes to fund state spending and state debt.

Finally, the under15 variable had a negative coefficient only for the 2000-2007 split of the data. This results could be due to the fact that after the Master Settlement Agreement in 1998, states with younger populations used alternative tools, other than the simply increasing the price of cigarettes, to deter youth smoking. The next chapter of this dissertation investigates the causes of tobacco control funding. 


\subsection{CONCLUSION}

This study found empirical evidence supporting the special interest group theory and spatial autocorrelation in policy implementation regarding cigarette excise taxation. Combining measures of tobacco special interest in a spatial econometric framework, this paper presented a new analysis of the magnitude of the special interest group effect. Accounting for the spillover effects of special interest due to both spatial interdependence in tax rate setting and the influence of neighboring state's tobacco special interest, increased the total magnitude of special interest effect six hundred percent compared to the baseline OLS. Therefore previous estimates of the impact of special interest groups, not estimated in a spatial framework, have substantially underestimated the total effect that special interest groups have on policy.

Using restricted time periods within the data, this paper also revealed the substantial changes in cigarette tax policy over the past 50 years. The data showed reversals in key explanatory variables in predicting the state-levied cigarette tax rate. The coefficients on the most recent data, from 2000-2007, revealed an opposite sign for a number of variables when compared to earlier subsets of the data. As the variance in interstate excise tax rates has changed, so has the degree to which excise tax rates were spatially correlated. The years from 1983 to 2000 exhibited the strongest degree of spatial correlation. Future research should further investigate the causes of this discrepancy in time and possibly more accurately identify when these changes took place. 


\subsection{APPENDIX}

This paper explores a number of robustness checks and alternative model specifications. Table A1 addresses the concern of multicollinearity arising from including various public finance variables on the right hand side of the estimation equation. Including both spending and revenue-raising variable simultaneously can potentially create unreliable effects estimates. Therefore, specification one removes all revenue-raising variables from the estimation specification; specification two drops all state spending variables from the model specification; and specification three includes no public finance variables.

Comparing the three model specifications, only marginal differences in coefficient magnitude are present. Both pounds and $\rho$ varied by a magnitude of 0.01 and were significant in every model specification. Similarly, each variable maintained the same sign for all three specifications. These results were also directly comparable to the results in Table 2, again, with only minor changes in coefficient magnitudes.

Table 6 provides the correlation matrix for the SDM independent variables presented in Table 2. The highest degree of correlation was between debt and healthcare, at 0.86 , and the spatially weighted wdebt and whealthcare, at 0.87 . Expectedly, some of the control variables were also highly correlated. Over 65 and under 15 had a correlation of 0.67 and the spatiallyweighted variables posted a correlation of 0.80 . The correlation between nominate and citizen, the two ideology variables, was 0.67 , illustrating that they provide differentiated measured of state-level ideology. Analyzing the entire matrix, multicollinearity does not appear to be a major concern. Table 5 provides additional support to this conclusion.

Table 7 introduces spatial fixed effects into the SDM equation to provide a different angle of analysis. With the spatial fixed effects included, the estimated coefficients measure 
within state variance rather than interstate variance. Therefore, the hypothesized signs of the variables in the spatial fixed effects model may be substantially different. The previous variables of interest, pounds and lobby are not anticipated to be statistically significant. In the fixed effects model, a marginal increase or decrease in the quantity of tobacco grown with in a state would not be expected to cause a change in tax policy, for example. Similarly, there has not been a large variance in the amount of tobacco produced by individual states over the time period covered by the data used in this study.

Ideological swings, on the other hand, may be just as equally prone to causing policy changes as differences in ideology across states that was hypothesized in Section III above. Also, including spatial fixed effects will absorb a large amount of the spatial variation across states, measured by $\rho$. Nevertheless, the SDM with spatial fixed effects does provide an additional perspective to the understanding of cigarette tax policy.

Table 7 presents three different model specifications using the SDM with spatial fixed effects. Columns one and two mirror the regression specification in Table 2, but include spatial fixed effects. Columns three and four similarly mirror the specification presented in Table 3 with spatial fixed effects included. Columns five and six differ slightly by presenting a SDM with spatial fixed effects, but without the public finance variables, as the public finance variables are highly correlated with the spatial fixed effects. Analyzing the results from Table 7 show, indeed, both pounds and lobby have substantially smaller coefficients than their coefficients in the interstate analysis and their coefficients are not statistically significant in each specification. The spatial dispersion parameter, $\rho$, also was substantially smaller and not statistically in any of the regressions in Table 7. 
In all three models, the nominate coefficient was positive and significant in the direct effects and total effects, indicating as the ideology of the politicians in the state moved further to the left, they were more likely to increase their cigarette tax rates. The direct effect coefficient of citizen, however, represents the opposite effect on tax rates. As citizen ideology moved further to the left, they demanded lower cigarette taxes. The effect is countered by a positive indirect effect, so that the total effect of a change in citizen is not statistically different from zero, but the direct effect indicates that the citizens may have influence within their own state.

Overall, all three model specifications were very similar to each other, suggesting the multicollinearity between the public finance variables and the spatial fixed effects is not a major concern. The spatial fixed effects model provides a widening of the analysis on cigarette excise taxation. 
Figure 1 Cigarette Tax Per Pack in 2007

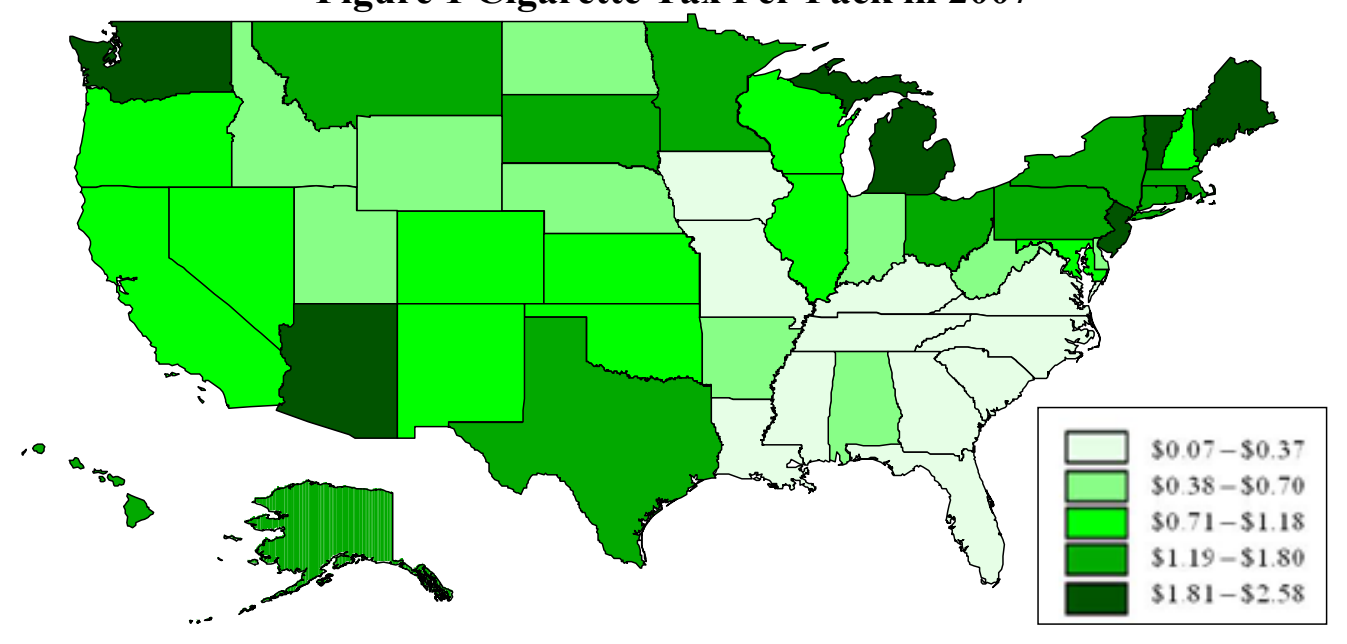

Figure 2 Pounds of Tobacco Produced by State in 2007

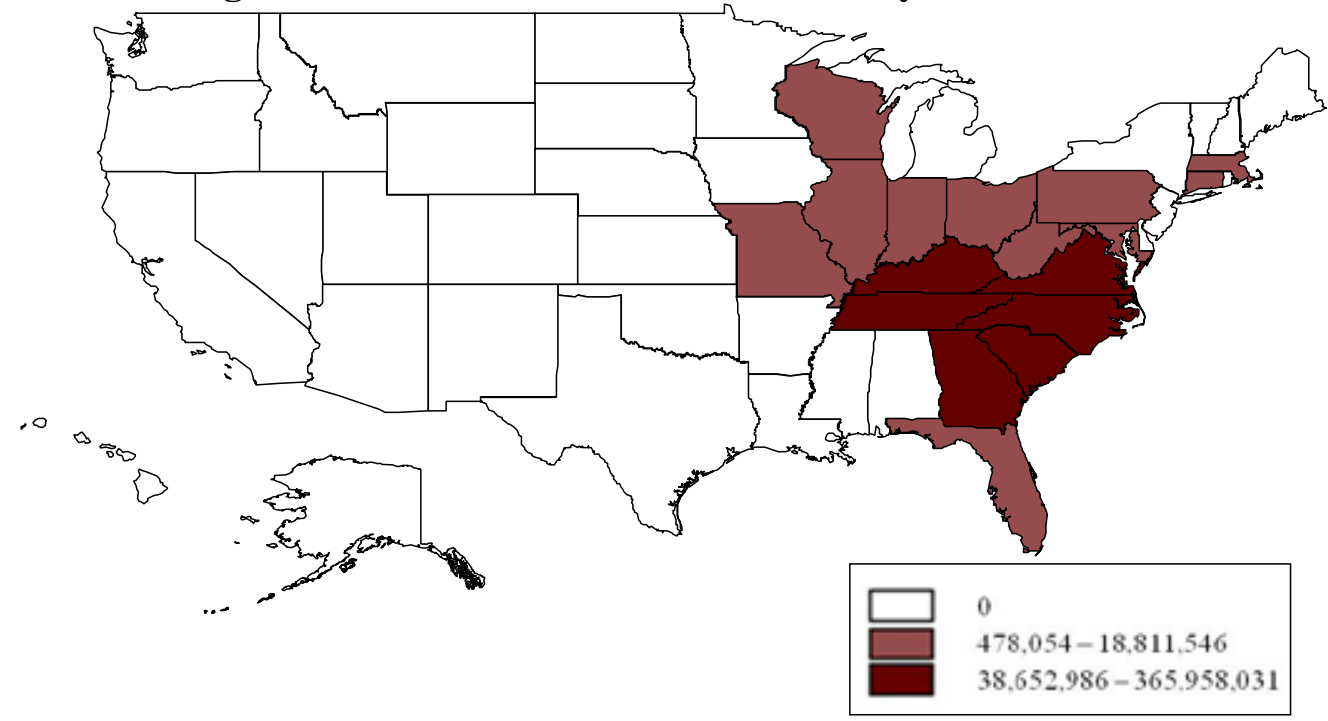




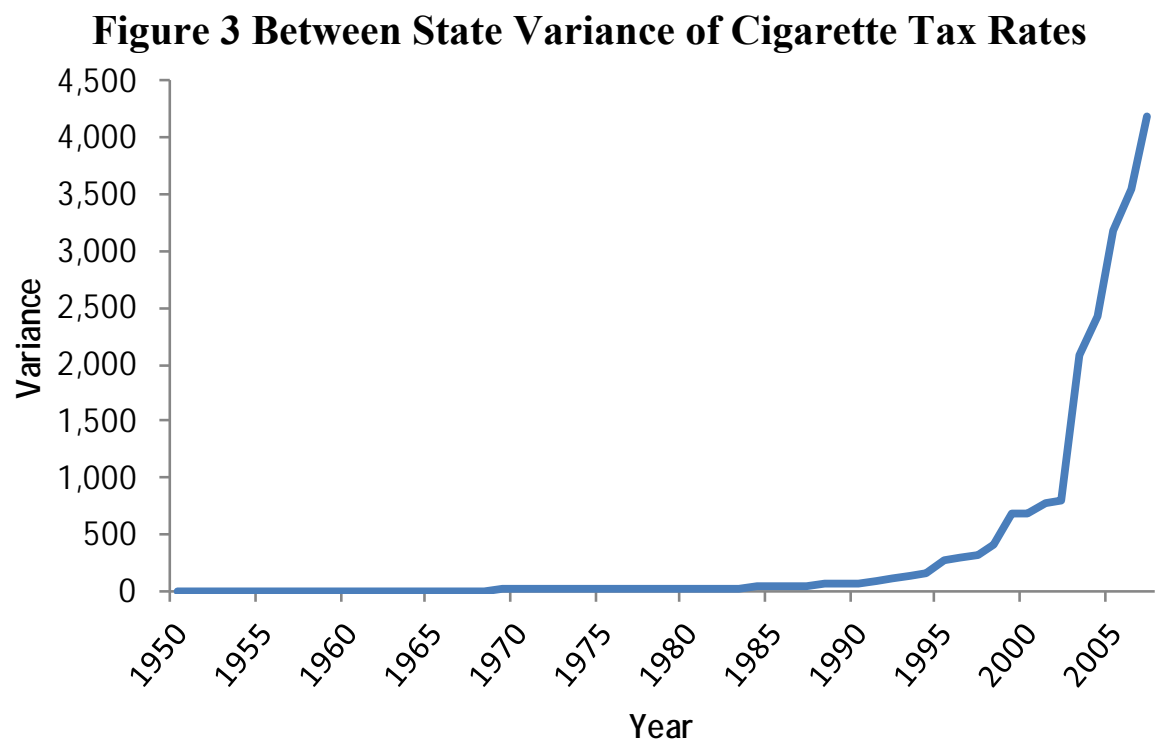

Table 1 Descriptive Statistics and LM Test Results

\begin{tabular}{llll} 
Variable & Mean & Std. Dev. & Source \\
Y & 65.90 & 51.47 & Orzechowski and Walker (2007) \\
$\mathrm{T}$ & 7.72 & 5.18 & Orzechowski and Walker (2007) \\
pounds & 17.71 & 63.26 & USDA Ag. Census \\
state lobby & 1198.60 & 6420.90 & Center for Responsive Politics \\
nominate & 49.57 & 24.77 & Berry et al. (2010) \\
citizen & 47.97 & 17.16 & Berry et al. (1998) \\
sales tax & 4.75 & 1.84 & Tax Foundation \\
no income tax & 0.18 & 0.38 & Tax Foundation \\
gini & 38.51 & 3.81 & Census Bureau \\
debt & 0.07 & 0.14 & State Government Finances - Census Bureau \\
health & 0.14 & 0.28 & State Government Finances - Census Bureau \\
under15 & 24.57 & 4.29 & Census Bureau \\
over65 & 11.21 & 2.39 & Census Bureau \\
urban & 72.56 & 15.34 & Census Bureau \\
white & 84.25 & 14.02 & Census Bureau \\
educ & 25.62 & 5.16 & Census Bureau \\
\hline LM Lag & $160.07 * * *$ & & \\
LM Error & $91.637 * * *$ & & \\
LM Lag Robust & $74.39 * * *$ & & \\
LM Error Robust & 0.42 & & \\
LM probability presented to the right of the LM tests \\
$* * *$ LM probability less that 0.01 & & \\
& & & \\
& &
\end{tabular}


Table 2 Determinants of State Cigarette Tax Rates

\begin{tabular}{|c|c|c|c|c|c|c|}
\hline & \multicolumn{2}{|c|}{ OLS } & \multicolumn{2}{|r|}{ SAR } & \multicolumn{2}{|c|}{ SDM } \\
\hline & $\beta$ & t-stat & $\beta$ & t-stat & $\beta$ & t-stat \\
\hline & \multicolumn{6}{|c|}{ Direct Effect Estimates } \\
\hline pounds & & & -0.11 & $-3.69 * * *$ & -0.18 & $-6.61 * * *$ \\
\hline nominate & & & 0.41 & $4.93 * * *$ & 0.32 & $4.41 * * *$ \\
\hline citizen & & & 0.38 & $1.92 *$ & 0.11 & 0.59 \\
\hline salestax & & & 3.12 & $2.89 * * *$ & 2.04 & 1.44 \\
\hline noincometax & & & 2.72 & 0.57 & -9.14 & -1.67 \\
\hline gini & & & -1.81 & $-2.76 * * *$ & 0.58 & 0.85 \\
\hline debt & & & 12.38 & 0.78 & -3.63 & -0.24 \\
\hline \multirow[t]{2}{*}{ healthcare } & & & -8.06 & -1.37 & -2.00 & -0.39 \\
\hline & \multicolumn{6}{|c|}{ Indirect Effect Estimates } \\
\hline pounds & & & -0.10 & $-2.86 * * *$ & -0.54 & $-5.67 * * *$ \\
\hline nominate & & & 0.37 & $3.35^{* * *}$ & -0.20 & -0.82 \\
\hline citizen & & & 0.34 & $1.82 *$ & 0.91 & $1.73 *$ \\
\hline salestax & & & 2.86 & 2.31 & -7.22 & -1.64 \\
\hline noincometax & & & 2.44 & 0.55 & -10.59 & -0.52 \\
\hline gini & & & -1.64 & $-2.36^{* *}$ & -7.14 & $-3.45 * * *$ \\
\hline debt & & & 10.87 & 0.74 & 120.92 & $2.70^{* * *}$ \\
\hline \multirow[t]{2}{*}{ healthcare } & & & -7.24 & -1.31 & -21.85 & -1.53 \\
\hline & \multicolumn{6}{|c|}{ Total Effect Estimates } \\
\hline pounds & -0.12 & $-4.13 * * *$ & -0.21 & $-3.41^{* * *}$ & -0.72 & $-6.71 * * *$ \\
\hline nominate & 0.44 & $5.12 * * *$ & 0.79 & $4.34^{* * *}$ & 0.13 & 0.46 \\
\hline citizen & 0.74 & $3.70 * * *$ & 0.72 & $1.91^{*}$ & 1.02 & $1.70^{*}$ \\
\hline salestax & 1.81 & 1.64 & 5.98 & $2.67 * * *$ & -5.18 & -0.93 \\
\hline noincometax & 6.03 & 1.21 & 5.17 & 0.56 & -19.74 & -0.82 \\
\hline gini & -2.71 & $-4.51 * * *$ & -3.45 & $-2.65 * * *$ & -6.55 & $-2.79 * * *$ \\
\hline debt & 31.77 & $1.87^{*}$ & 23.25 & 0.77 & 117.30 & $2.26^{* *}$ \\
\hline healthcare & -13.20 & $-2.13^{* *}$ & -15.30 & -1.36 & -23.85 & -1.49 \\
\hline$\rho$ & & & 0.50 & $9.29 * * *$ & 0.22 & $3.15^{* * *}$ \\
\hline $\mathrm{N}$ & 408 & & 408 & & 408 & \\
\hline R squared & 0.54 & & 0.63 & & 0.71 & \\
\hline Log likelihoo & & & -1994.6 & & -1932.3 & \\
\hline
\end{tabular}

The dependent variable in all model specifications is U.S. state level cigarette excise tax per pack, in cents. All regressions include time period fixed effects and state controls measuring the percentage of Caucasian population, percentage of population living in an urban area, percentage of the state population having earned a bachelor's degree or higher, percentage of a state's population over the age of 65, and percentage of a state's population under the age of 15 . All revenue variables are in real, per capita measures. 
Table 3 Determinants of State Cigarette Tax Rates with Alternative Special-Interest Measure

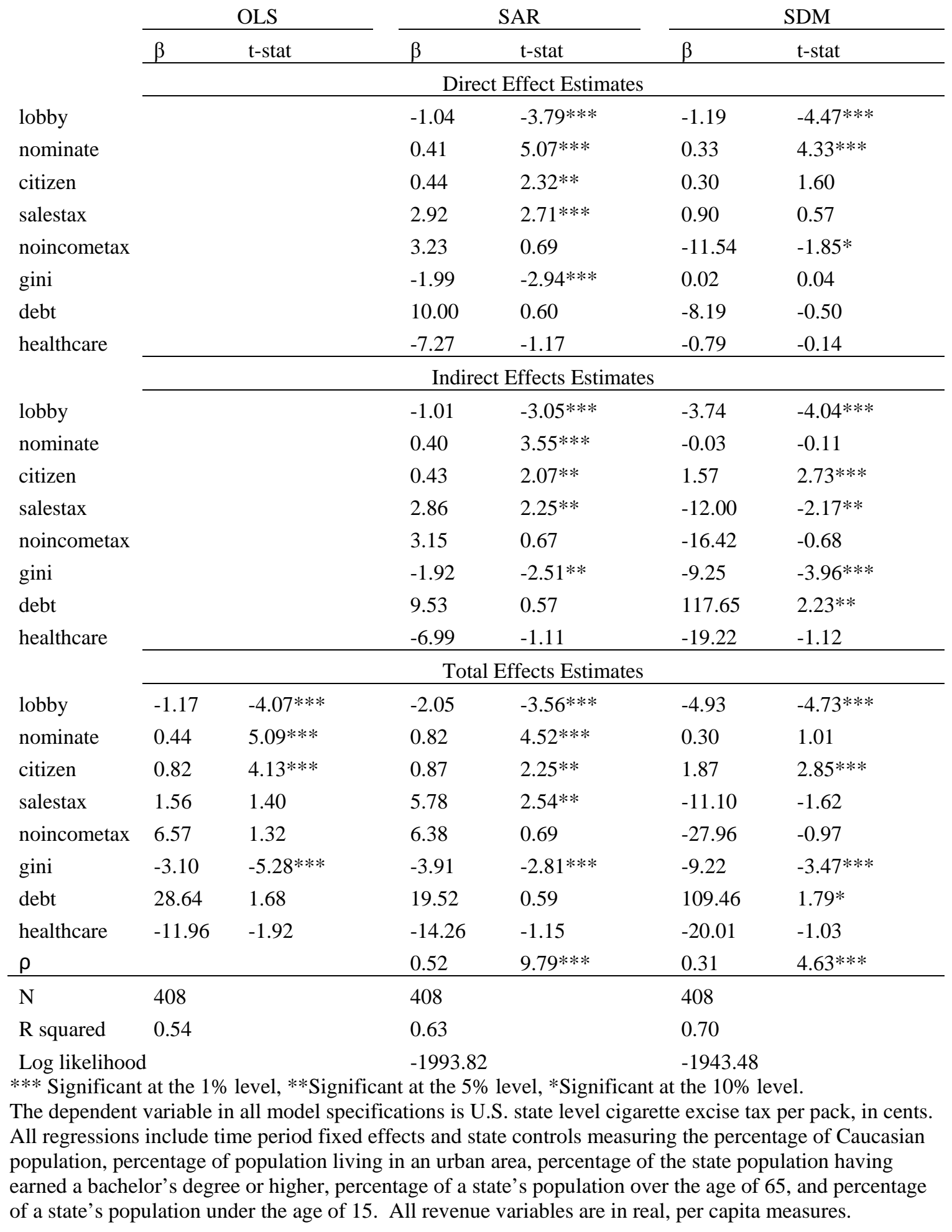


Table 4 SDM Using Restricted Time Period Data

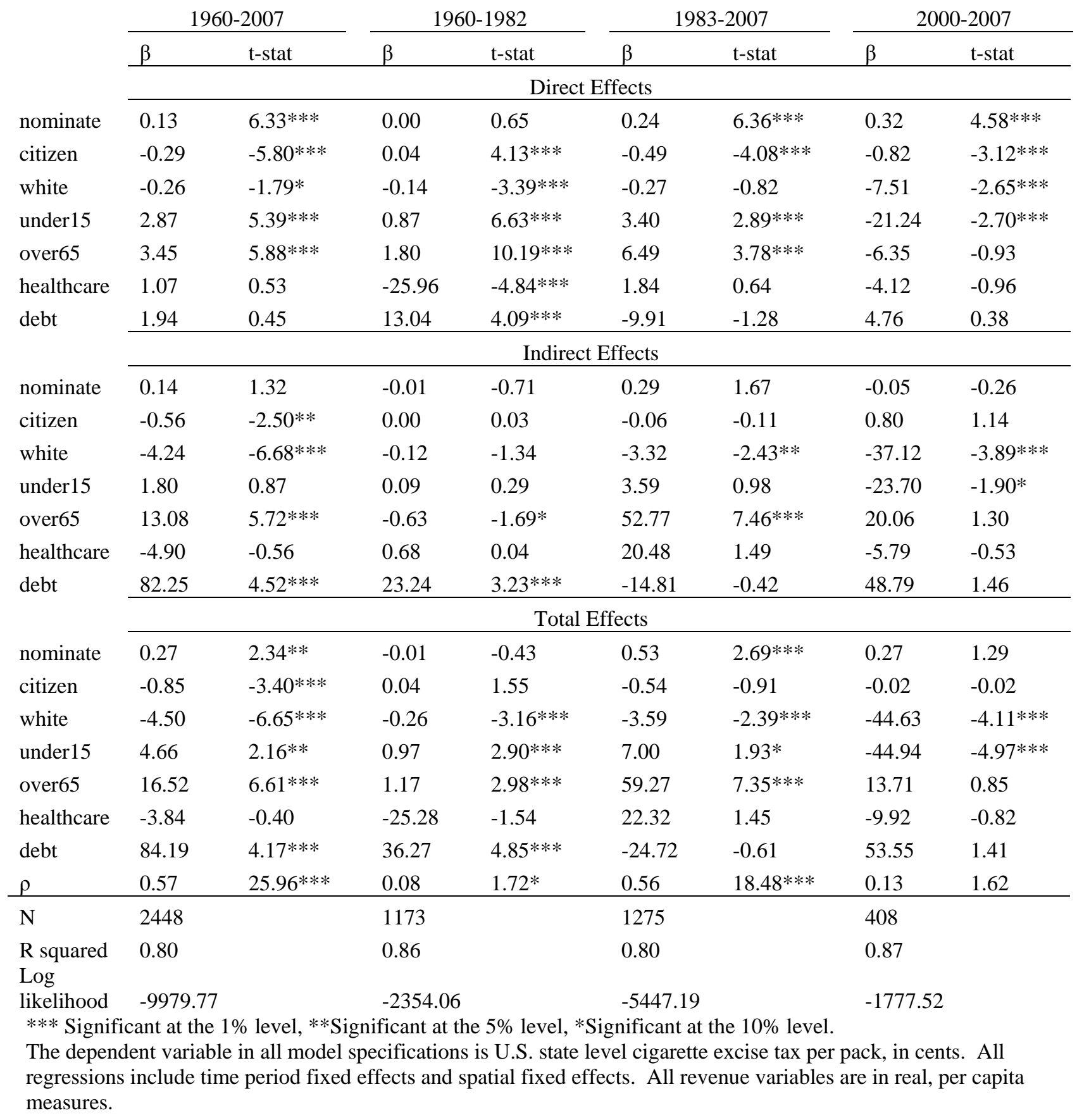


Table 5 Public Finance Variables Alternative Model Specification Robustness Checks

\begin{tabular}{|c|c|c|c|c|c|c|}
\hline & \multicolumn{2}{|c|}{ No Revenue-Raising Vars. } & \multicolumn{2}{|c|}{ No Spending Vars. } & \multicolumn{2}{|c|}{ No Public Finance Vars. } \\
\hline & $\underline{\beta}$ & t-stat & $\beta$ & t-stat & $\beta$ & t-stat \\
\hline & \multicolumn{6}{|c|}{ Direct Effects Estimates } \\
\hline pounds & -0.17 & $-6.49 * * *$ & -0.18 & $-6.32 * * *$ & -0.17 & $-5.86 * * *$ \\
\hline nominate & 0.36 & $4.91^{* * *}$ & 0.37 & $4.83^{* * *}$ & 0.38 & $5.11^{* * *}$ \\
\hline citizen & 0.25 & 1.46 & 0.18 & 1.05 & 0.27 & 1.57 \\
\hline salestax & & & 1.43 & 1.18 & & \\
\hline gini & 1.00 & 1.57 & 0.45 & 0.65 & 0.68 & 1.06 \\
\hline debt & -8.31 & -0.54 & & & & \\
\hline \multirow[t]{2}{*}{ healthcare } & $\underline{-0.30}$ & -0.06 & & & & \\
\hline & \multicolumn{6}{|c|}{ Indirect Effects Estimates } \\
\hline pounds & -0.57 & $-6.10 * * *$ & -0.58 & $-6.14 * * *$ & -0.61 & $-6.67 * * *$ \\
\hline nominate & -0.22 & -0.90 & -0.17 & -0.75 & -0.21 & -0.91 \\
\hline citizen & 0.60 & 1.26 & 1.05 & $2.08^{* *}$ & 0.72 & 1.49 \\
\hline salestax & & & -8.22 & $-2.29 * *$ & & \\
\hline gini & -6.93 & $-4.04 * * *$ & -5.48 & $-2.74 * * *$ & -6.59 & $-3.96 * * *$ \\
\hline debt & 110.99 & $2.74 * * *$ & & & & \\
\hline \multirow[t]{2}{*}{ healthcare } & $\underline{-20.27}$ & -1.43 & & & & \\
\hline & \multicolumn{6}{|c|}{ Total Effects Estimate } \\
\hline pounds & -0.74 & $-6.98 * * *$ & -0.76 & $-7.05 * * *$ & -0.78 & $-7.37 * * *$ \\
\hline nominate & 0.15 & 0.55 & 0.19 & 0.76 & 0.17 & 0.66 \\
\hline citizen & 0.85 & 1.57 & 1.23 & $2.17 * *$ & 0.99 & $1.81^{*}$ \\
\hline salestax & & & -6.79 & -1.52 & & \\
\hline gini & -5.93 & $-3.08 * * *$ & -5.04 & $-2.18 * *$ & -5.91 & $-3.24 * * *$ \\
\hline debt & 102.68 & $2.27 * *$ & & & & \\
\hline healthcare & -20.57 & -1.33 & & & & \\
\hline$\rho$ & 0.20 & $2.79 * * *$ & 0.21 & $2.96 * * *$ & 0.20 & $2.75^{* * *}$ \\
\hline $\mathrm{N}$ & 408 & & 408 & & 408 & \\
\hline R squared & 0.70 & & 0.70 & & 0.69 & \\
\hline Log likelihood & -1941.97 & & -1940.75 & & -1949.32 & \\
\hline
\end{tabular}




\section{Table 6 Correlation Matrix of the SDM Specification used in Table 2}

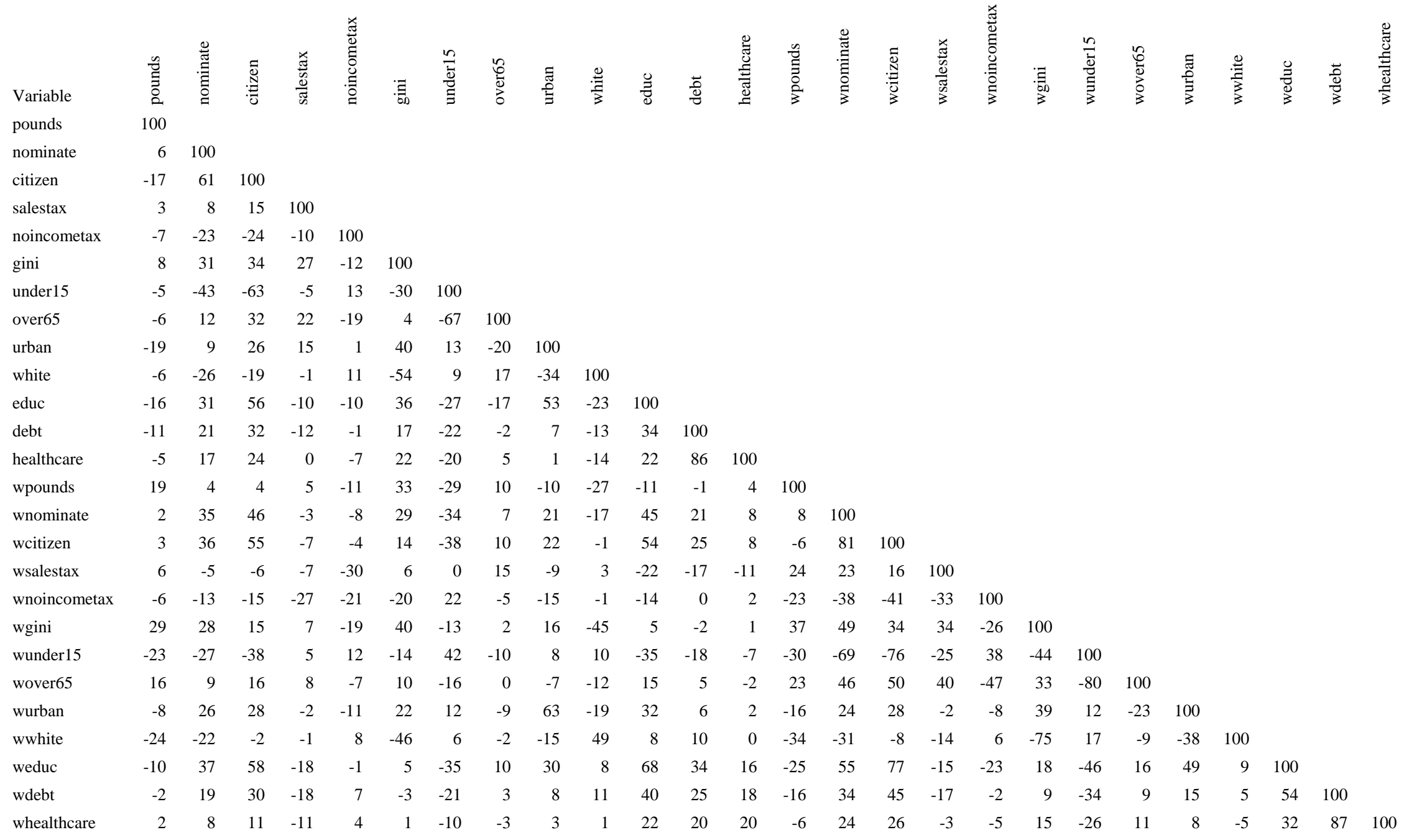


Table 7 Within State Analysis Using Spatial Durbin Model Specifications

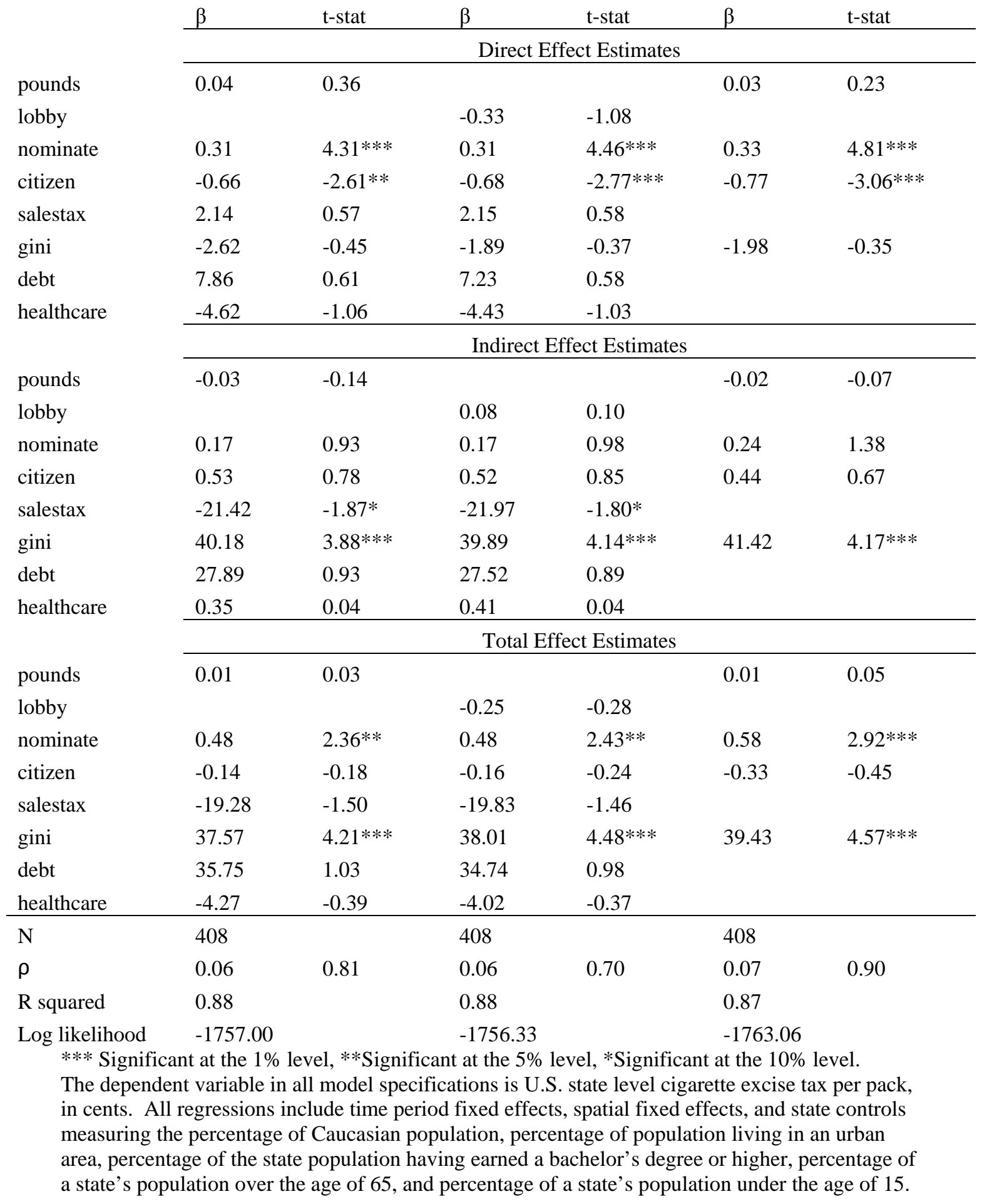




\section{Chapter 3}

\section{Reevaluating Horizontal Tax Competition}

\subsection{INTRODUCTION}

A recent development in the literature has been to examine tax competition. Tax competition between neighboring states is denoted as horizontal competition and tax competition between states and the federal government is denoted as vertical competition. These multiple governments are often viewed as competitors over the same tax base. For this reason, states may choose to strategically set and adjust their tax rates according to the actions of their competitors. Due to the a number of characteristics of cigarettes and cigarette demand, discussed in more detail later in the paper, cigarette excise taxes are prone to horizontal tax competition, rather than vertical tax completion.

If horizontal competition is conducted over cigarette excise tax rates, than a state will adjust its tax rate in response to a competitor, or neighbor, modifying their rate. If a state increases its tax rate in response to a competitor's increase, this is denoted as a positive horizontal response function, or positive horizontal competition. Conversely, if a state decreases its tax rate in response to a competitor increasing their rate, this is denoted as negative horizontal competition.

If the horizontal reaction function were positive, then any cigarette tax rate increase would lead to a series of corresponding increases from neighbors in the following period, proceeded by an increase by the neighbors of the neighbors (including the original state causing the tax rate shock) in the period afterwards, resulting in an upward spiral until an increase in the tax rate would lead to a decrease in the present discounted value of future cigarette tax revenue. Given that politicians have an extreme preference for the present, highly discounting the future 
due to pressure from the political cycle a downward trend in cigarette consumption across the U.S., and the fiscal stress facing a number of states, the equilibrium created from a situation of a positive horizontal reaction function would be one where cigarette tax rates would be high enough so that a further increase in the tax rate would generate, at most, only modest increases in revenue.

This is not the case according to cigarette tax rate and revenue data from the last two decades. Farrelly, Nimsch, and James (2003) analyze 33 state cigarette tax rate increases from 1990 to 2000. These tax rates increase one-year revenues between 13.3 percent and 221.6 percent. A number of these states have since increased their tax rate again, illustrating that states have not reached the point at which additional tax rate hikes will decrease revenue.

In the case of positive horizontal competition, a highly likely scenario would materialize only a few periods after any initial tax rate increase in the process of arriving at the revenue maximizing condition. Every state would be increasing their tax rate. Due to the spatial interdependence of policy, it would take only a few periods for any shock to spread to every state in the country. Depending on the magnitude of the spatial interaction, this scenario could be reached as quickly as one period after the initial shock (i.e. a shock generating in Missouri influencing, even marginally, six neighbors, would have an impact on every U.S. contiguous state).

Again, the scenario of constant state tax rate increases from every U.S. state is not observed in the data. In 2007, only 9 states increased their tax rates compared to 11 states in 2006, and 23 states in 2004.

This paper, therefore, explores an alternative possibility to the positive horizontal reaction function. By implementing a dynamic space time panel model, and highlighting why a 
number of coefficients attempting to calculate the horizontal aspect of tax competition are upwardly biased, this study aims to estimate more accurate horizontal response function, detailing a more appropriate method for estimating horizontal tax competition.

\subsection{LITERATURE REVIEW}

LeSage and Dominguez (2010) emphasize and demonstrate the need to incorporate spatial effects into the public economics literature. Overlooking or omitting spatial correlation may mean omitting an extremely influential factor in government decision making. Econometrically, any regression that excludes these spatial factors will be biased and inefficient if the spatial correlation is located in the dependent variable or inefficient if the spatial correlation is found in the error term (LeSage and Pace, 2009; 2010). Fortunately, recent econometric innovation has enabled simple and proper testing for spatial dependencies and the inclusion of spatial effects into empirical regressions.

Devereux, Lockwood, and Redoano (2007) provide the most recent theoretical framework for the reaction function of excise taxes. They combine the standard model of vertical reaction functions from Keen (1998) with the horizontal competition model from Kanbur and Keen (1993) and Nielson (2001). Their results, consistent with economic theory, suggest that the state tax responses will depend on the price elasticity of demand for the good and the incentives for inter-state arbitrage (cross-border shopping). If individual demand is relatively price inelastic and the incentives for cross-border shopping are strong, states should be strongly horizontally competitive, but unresponsive to federal (vertical) tax changes. If price demand is relatively elastic and cross-border shopping incentives are weak, state taxes will be unresponsive to horizontal changes in tax rates, but will respond to federal tax changes either positively or negatively. Cigarette taxes obviously fall into the first of these two scenarios. Empirically 
testing this hypothesis, Devereux, Lockwood, and Redoano (2007) find that when accounting for both vertical and horizontal competition in cigarette excise taxation, the federal tax rate is not significantly different from zero, while the weighted neighbor's tax rates are positive and significant.

Fredrickson and Mamun (2008) investigate vertical competition with data encompassing 1975-2001. Estimating a multitude of model specifications, they find a significant negative reaction function for states responding to the federal cigarette tax. They test horizontal competition in one model, finding a positive coefficient for the horizontal interaction. They also find tobacco income positive and significant in a majority of specifications, all including state fixed effects.

Besley and Rosen (1998) use panel data spanning 1975-1989, focused on a reaction function from state taxation policy to a change in the federal tax policy. They find a positive reaction response from state to an increase in the federal tax.

By making certain assumptions in their model specifications these previous studies are not estimating the most accurate measure of the horizontal reaction function. A common method of measuring tax competition has been to estimate the impact of $\rho \mathrm{WY}$ on $\mathrm{Y}$ by leaving $\rho \mathrm{WY}$ on the right hand side of the equation, using IV (most commonly the lagged value of Y), 2SLS, or GMM to address the natural endogineity arising from having $\rho \mathrm{WY}$ as an explanatory variable (Brulhart and Jametti, 2006, 2008; Fredrickson and Mamun, 2008; Egger, Pfaffermayr, and Winner, 2005; Rork, 2003; and Rizzo, 2010). However, LeSage and Pace (2009) advocate the use of a SAR or a SDM, estimated using maximum likelihood, in the case of a spatially correlated dependent variable. 
These studies that use $\rho \mathrm{WY}$ reveal that excise taxes are correlated at an individual time period, $t$, but they do not yield a dynamic picture of how neighboring states react to one another. Other studies have lagged the values of the weighted neighbor's tax rates, $\rho \mathrm{WY} \mathrm{t}_{\mathrm{t}-1}$ and asserted that this value was the more accurate measure of the horizontal reaction function (Nelson, 2002; and Fox, Hill, and Murray, 2010). While lagging the weighted value of the neighboring state's tax rates does give a more accurate measure of a reaction function by introducing a dynamic aspect, this still falls short of the best measure for horizontal competition. It is likely that $\rho \mathrm{WY}_{\mathrm{t}}$ ${ }_{1}$ is the most accurate predictor for $\rho \mathrm{W} \mathrm{Y}_{\mathrm{t}}$, which indirectly affects $\mathrm{Y}_{\mathrm{t}}$. A model specification which includes only $\rho \mathrm{WY}{ }_{\mathrm{t}-1}$ to measure horizontal interactions excludes the autoregressive aspect of the data by assuming $\rho=0$ in time $t$. These models also fail to account for the persistent nature of tax rates by including a lagged measure of the state's own tax rate. If the state's own lagged tax rate is omitted or if $\rho$ is incorrectly assumed to be zero, the $\rho \mathrm{WY} \mathrm{t}_{\mathrm{t}-1}$ term used to measure horizontal competition will be upwardly biased.

Devereux, Lockwood, and Redoano (2007) presents the model specification closest to ideal thus far, by using an estimating equation with the lagged value $\mathrm{Y}_{\mathrm{t}-1}$ and $\rho \mathrm{WY}$ on the right hand side. This equation still does not account for the fact that excise tax rates are correlated not only in $t-1$, but all time periods, including time $t$. Therefore the Devereux et al. model can also be expanded to find a more accurate measure of tax competition.

\subsection{DATA AND MODEL}

This study follows a model introduced by Debrarsy, Ertur, and LeSage (2011), in order to properly account for cigarette tax rate correlation over both time and space. This model will provide the most accurate measure of how states respond to a change in a neighboring state's tax rate, i.e. horizontal competition. The random effects dynamic space-time panel model is, 


$$
\mathrm{Y}_{\mathrm{t}}=\varphi \mathrm{Y}_{\mathrm{t}-1}+\rho \mathrm{WY}_{\mathrm{t}}+\theta \mathrm{W} \mathrm{Y}_{\mathrm{t}-1}+\iota_{N} \alpha+\mathrm{X}_{\mathrm{t}} \beta+\mathrm{WX}_{\mathrm{t}} \gamma+\left(\mu_{\mathrm{t}}+\varepsilon_{\mathrm{t}}\right),
$$

where $\mathrm{Y}$ is the state's cigarette tax rate at time, $\mathrm{t} ; \mathrm{W}$ is a contiguity based weight matrix; an intercept term, $\alpha ; \mathrm{X}$ is a matrix of explanatory variables including nominate, a NOMINATE measure of state ideology from Berry et al. (2010), citizen, an ideology measure of a state's citizens from Berry et al (1998), state demographic variables, under15, over65, and white, which account for the proportion of a state's population that is under the age of 15 , over the age of 65 , and Caucasian, respectively; and state finance variables, interest and healthcare, which account for the per capita amount of government spending on interest on state debt and state heath care expenditures, respectively; and the random effects model error term is $\mu+\varepsilon$.

The data cover all U.S. states plus Washington D.C. from 1960-2007. Descriptive statistics of the variables are presented in Table 8. W assigns neighbors via geographic contiguity, i.e. border-sharing. This weight matrix was selected as contiguity-based, as horizontal competition is typically measured via cross-border shopping, which most commonly occurs between states that share a border. State politicians also model their policies most closely to their bordering states, as discussed in Chapter 1.

Following Debrarsy et al. (2011) (1) is transformed using a time filter and a space filter. The time filter, $\mathrm{A}$, is a $\mathrm{T}+1, \mathrm{~T}+1$ matrix containing a Praise-Winsten transformation for the initial period, using the 1960 data as the values for the initial period. The spatial filter, B, is a nonsingular matrix, such that $\mathrm{B}=\left(\mathrm{I}_{\mathrm{N}^{-}} \rho \mathrm{W}\right)^{-1}$. The time filter and the spatial filter are combined using a Kronecker product,

$\mathrm{A} \otimes \mathrm{B}=\mathrm{I}_{\mathrm{N}, \mathrm{T}+1}-\rho \mathrm{I}_{\mathrm{T}+1} \otimes \mathrm{W}-\varphi \mathrm{L} \otimes \mathrm{I}_{\mathrm{N}}+(\rho \varphi) \mathrm{L} \otimes \mathrm{W}$, where $\mathrm{L}$ is the $(\mathrm{T}+1)(\mathrm{T}+1)$ matrix time-lag operator. This filter restriction implies that $\theta$, the lagged spatial interaction parameter is equal to $-\rho \varphi$. This restriction indicates that the space and 
time effects are separable, thereby simplifying the space-time covariance structure along with the cross-partial derivatives used to interpret the model.

The estimation model becomes,

(2) $\mathrm{Y}=\mathrm{Q}^{-1}\left[\iota_{N T} \alpha+\mathrm{X} \beta+\mathrm{WX} \gamma+\mathrm{H} \mu+\varepsilon\right]$, where

$\mathrm{Q}=\left(\begin{array}{cccccc}\mathrm{B} & 0 & & & 0 & 0 \\ \mathrm{~A} & \mathrm{~B} & \cdots & & 0 \\ 0 & \mathrm{~A} & & & & \\ & \vdots & & \ddots & & \vdots \\ 0 & 0 & \cdots & \mathrm{A} & \mathrm{B}\end{array}\right)$,

$A=-\left(\varphi \mathbf{I}_{N}+\theta W\right)$,

$\mathrm{B}=\left(\mathrm{I}_{\mathrm{N}}+\rho \mathrm{W}\right)$,

, and $\mathrm{H}=\iota_{T} \otimes \mathrm{I}_{\mathrm{N}}$ is a matrix of $\mathrm{N}$ random effects to each region for all time periods. Again following Debrarsy et al. (2011), this study employs a Bayesian Markov Chain Monte Carlo (MCMC) estimation scheme to produce estimates of the parameters in (2). A prior distribution $\mathrm{p}\left(\alpha, \beta, \gamma, \sigma_{\mu}^{2}, \sigma_{\varepsilon}^{2}, \rho, \varphi, \theta\right)$ is assigned such that all parameters are a priori independent. $\alpha$ and $\beta$ are estimated separately, assuming a non-hierarchical prior of the independent Normal-Gamma variety,

$\alpha \sim \mathrm{N}\left(\alpha_{0}, \mathrm{M}_{\alpha}^{-1}\right)$

$\beta \sim \mathrm{N}\left(\beta_{0}, \mathrm{M}_{\beta}^{-1}\right)$

$\sigma_{\varepsilon}^{-2} \sim \mathrm{G}\left(v_{0} / 2, S_{0} / 2\right)$

$\sigma_{\mu}^{-2} \sim \mathrm{G}\left(v_{1} / 2, S_{1} / 2\right)$

The parameters are assigned with diffuse priors, $\alpha_{0}=\beta_{0}=0$, the precision parameter $\mathrm{M}_{\alpha}^{-1}$ set to $10^{12}, \mathrm{M}_{\beta}^{-1}$ set to $10^{12} \mathrm{I}_{\mathrm{K}}$ and the Gamma priors are set to 0.001 . As suggested by Chib and Carlin (1999), $\beta$ is sampled first, marginalized over $\mu$, and then $\mu$ is sampled, conditional on $\beta$. 
The model is then estimated using 10,000 MCMC draws, discarding the first 2,000 as a burn-in for the sampler. The standard posterior distributions, illustrated in Koop (2003), are used to analyze the model results.

The aim of this study is to analyze the partial derivatives arising from changing the explanatory variables in (1). Debrarsy et al. (2011) describe the proper interpretation of these own- and cross-partial derivatives. $\partial y_{i t} / \partial X_{i t}^{r}$ represents the contemporaneous direct effect on state i's tax rate (y) produced from a change in the $\mathrm{r}^{\text {th }}$ explanatory variable in state $\mathrm{i}$. Changes in that same $\mathrm{r}^{\text {th }}$ explanatory variable in state $\mathrm{i}$ create a spillover effect, $\partial y_{j t} / \partial X_{i t}^{r}$, in state $\mathrm{j}, \mathrm{j} \neq \mathrm{i}$, resulting from the cross-partial derivative.

The most advantageous component of the model for this study is that the dynamic space time model also allows for the estimation of partial derivatives that quantify the magnitude and timing of dependent responses. Therefore, the effect on a state's tax rate of a change in an explanatory variable in time, $t$, can be calculated for the time horizon, $t+T$. These effects are calculated as the partial derivatives, $\partial y_{i t+T} / \partial X_{i t}^{r}$ for time-space direct effects of state $\mathrm{i}$, and $\partial y_{j t+T} / \partial X_{i t}^{r}$ for the time-space indirect effects resulting in state $\mathrm{j}$ from a change in explanatory variable $r$ in state $i, j \neq i$, $T$ periods apart.

Using this model allows for separate estimation of time interdependence, space interdependence, and space-time interdependence. $\varphi$ is the parameter capturing the persistence in a state's tax rate over time. Obviously, state tax rates are highly persistent, so $\varphi$ is expected to be positive and close to unitary. $\rho$ measures the degree to which state tax rates are correlated over space. The previous chapter of this dissertation illustrated that across states, there exists a high degree of spatial autocorrelation across states, so $\rho$ is anticipated to be positive. $\theta$, therefore, becomes the measure of horizontal competition, quantifying the impact on state, i, of a 
one cent change in neighbor's tax rate in a previous period. Previous attempts to estimate $\theta$ in the literature have resulted in positive coefficients, though as previously mentioned, these are upwardly biased.

\subsection{RESULTS}

\subsubsection{Nested Models}

To present evidence similar to those found in the literature, Table 9 presents a number of model specifications designed to illustrate the time and/or space dependence. Models one through three present OLS estimations, assuming $\rho=0$, while models four and five drop that assumption, using a spatial Durbin model (SDM). The spatially weighted variables are denoted with a $\mathrm{W}^{*}$ before their variable name.

Model one illustrates the time dependence in cigarette excise taxes, as the one period lag was positive, near unity, and significant. Model two presents a specification similar to that in the literature attempting to estimate the horizontal reaction function. Clearly, by omitting the inertia from the time dependence of tax rates, the lagged neighbor's tax rate is upwardly biased. Model three, while including both the lagged time and space component, still produces upwardly biased results due to the assumption $\rho=0$, as state tax rates should be spatially correlated in time $t$ as well as previous time periods.

Models four and five utilize a SDM specification, both finding the $\rho$ parameter to be positive and highly statistically significant. This finding supports the hypothesis that the OLS models will be biased and inefficient. Model four illustrates that even a spatial model that includes an estimation of $\rho$, while also accounting for the time dependence in tax rates, produces a biased coefficient due to the improper assumption $\theta=0$. Finally, model five illustrates the biased coefficient of $\theta$, assuming $\varphi=0$. Assuming that any of $\varphi, \theta, \rho$ equal to zero will bias the 
remaining coefficients, leading to a misrepresentation of tax rates over both time and space. Therefore, the nonnested model is estimated in Section B.

\subsubsection{Time and Space Dependence}

Table 10 presents the mean parameter estimates along with the upper and lower 0.01 and 0.05 percentiles based on the 10,000 MCMC draws (2,000 burn in). Debarsy et al. (2011) note that these estimates should reflect mostly sample data and be roughly equivalent to the estimates from a maximum likelihood estimation.

In Bayesian estimations, if range between the upper 0.99 and lower 0.01 percentile draws does not span zero (i.e. both upper and lower are positive or both upper and lower are negative), than the null hypothesis of the parameter estimate equal to zero can be rejected with 99 percent confidence. This is analogous to a t-statistic p-value of less than 0.01 in absolute value.

Table 10 shows positive time and space dependence using the 0.01 and 0.99 intervals, with time dependence being substantially stronger than contemporaneous space dependence; $\varphi$, a mean of 0.7414 was more than twice as large as $\rho$, with a mean of 0.3484 . The posterior distribution of cross-product term, $-\varphi \rho$ appears consistent with time-space separability, as its mean is consistent with multiplying the means of the estimated $\varphi$ and $\rho$.

The lag spatial measure, $\theta$, was negative using the 0.01 and 0.99 intervals, highlighting counteracting spatial forces resulting from a change in a neighbor's tax rate. The spatial lag would suggest that a one cent increase in a neighbor's tax rate in a previous period would lead to a decrease in a state's own tax rate, averaging -0.1744 cents. This has a number of economic explanations and implications. Because tax policy can be heavily influenced by a number of political factors, as demonstrated in the previous chapter, the outlook for politicians must be considered when interpreting this coefficient. 
A neighboring state increasing their tax rate provides two benefits to the political party in power, a positive tax revenue externality and a more favorable yardstick for comparison. The higher tax rate in a neighboring state allows the party in power to increase their tax revenue by increasing their tax base, rather than through a rate increase of their own. Their tax base grows because a state either gains additional cross-border shoppers from an even greater gap in the tax rates between their state and their neighbor state or they will lose less of their own residents to cross-border shopping in the neighboring state, depending on the relative tax rates between the two states. Therefore, politicians are able to increase tax revenue without passing unpopular tax rate hikes.

Secondly, if politicians are concerned about yardstick competition, a politician will improve relative to a neighboring politician who raises taxes in their district. This gives yet another incentive for a politician to not respond with a tax rate increase of their own.

Combining the contemporaneous and lag spatial effects, however, the result remains one of positive horizontal competition, though the magnitude is reduced by half when combining $\rho$ and $\theta$. The draw to cut tax rates is outweighed by the lure to increase tax rates to obtain more revenue.

\subsubsection{Space-Time Direct, Indirect, and Total Effects}

Because this study utilizes both a time and space filter, the direct, indirect, and total effects estimations will disperse over both time and space. This section presents the contemporaneous direct, indirect, and total effects of a change in each explanatory variable out to 47 time periods. Table 11 presents the direct effects; Table 5 presents the indirect effects; and Table 6 presents the total effects. These tables present the marginal, single-period impact of a change in that variable at $t=0$ in column 3 . As $t$ goes to infinity, the impact of the shock at $t=0$ 
approaches zero. The cumulative effects are the sum of all the previous marginal effects and are presented in column two. The remaining columns provide the upper 0.99 and 0.95 and the lower 0.01 and 0.05 parameter intervals.

The direct effect estimates in Table 11 show coefficients that include zero for both of the ideology variables and most of the state characteristic variable's confidence intervals. Interest, however, had a positive coefficient within the 99 percent confidence interval. This suggests that states with larger debt payments had higher cigarette tax rates. While the one-period effect of having an additional one dollar of per capita debt expenditure related to a higher cigarette tax rate of only 5.59 cents, the cumulative effect was 22.09 cents after 10 years and 23.75 cents after 47 years. Healthcare, on the other hand, had a negative coefficient in the 99 percent confidence level, with a cumulative magnitude of -0.14 cents.

Table 12 illustrates the space-time indirect effects and Table 13 shows the space-time total effects. Unfortunately, all of the independent variables had coefficients which included zero in their confidence intervals, suggesting that the independent variables did not exhibit strong spatial spillover effects. The insignificant coefficients from the indirect effects consequently lead to similar results in the total effects estimations, as the confidence intervals included zero for all of the independent variables.

\subsection{CONCLUSION}

The study reexamines horizontal tax competition using a panel of U.S. state-level cigarette excise tax rates. This study was motivated by trends in the data that are not directly comparable with the results that would be suggested by a strong positive horizontal response function; states have still be able to increase revenue in the short run from increase tax rates and only a small sample of states increase their tax rate each year. 
This study expands the literature by accounting for simultaneous time and spatial dependence in cigarette excise taxation. To do so, a dynamic space time panel model is exploited. Overall, this paper finds that both time and spatial effects are significant in determining the level of cigarette excise tax rates. Combining a lagged spatial effect with a contemporaneous spatial effect, the horizontal response function was found to be positive, but smaller in magnitude than when either effect is excluded from the model specification. A number of political economy factors support this constraint on the horizontal response function, including politicians capitalizing on the externality of tax revenue growth and relative improvement via yardstick competition resulting from having a neighboring state increase its tax rate and not responding with a tax increase of their own. 


\section{Table 8 Descriptive Statistics}

Variable

Y

nominate

citizen

under 15

over65

urban

white

debt

healthcare
Mean

65.90

49.57

47.97

24.57

11.21

72.56

84.25

0.07

0.14
Std. Dev. Source

51.47

24.77

17.16

4.29

2.39

15.34

14.02

0.14

0.28
Orzechowski and Walker (2007)

Berry et al. (2010)

Berry et al. (1998)

Census Bureau

Census Bureau

Census Bureau

Census Bureau

State Government Finances - Census Bureau

State Government Finances - Census Bureau 
Table 9 OLS and SDM Replications of Previous Model Specifications Used in the Literature

\begin{tabular}{|c|c|c|c|c|c|c|c|c|c|c|}
\hline \multirow{2}{*}{$\begin{array}{l}\text { Model } \\
\text { Variable }\end{array}$} & \multicolumn{2}{|c|}{ OLS } & \multicolumn{2}{|c|}{ OLS } & \multicolumn{2}{|c|}{ OLS } & \multicolumn{2}{|c|}{ SDM } & \multicolumn{2}{|c|}{ SDM } \\
\hline & $\beta$ & t-statistic & $\beta$ & t-statistic & $\beta$ & t-statistic & total & t- statistic & total & t- statistic \\
\hline$Y_{t-1}$ & 1.029 & $123.810 * * *$ & & & 0.981 & $76.328 * * *$ & 1.089 & $90.253 * * *$ & & \\
\hline $\mathrm{W}^{*} \mathrm{Y}_{\mathrm{t}-1}$ & & & 1.084 & $53.375 * * *$ & 0.083 & $4.868 * * *$ & & & 1.082 & $40.709 * * *$ \\
\hline nominate & 0.005 & 0.504 & 0.067 & $3.603 * * *$ & 0.010 & 0.947 & 0.016 & 1.378 & 0.089 & $3.612 * * *$ \\
\hline citizen & 0.000 & 0.011 & 0.094 & $2.679 * * *$ & 0.002 & 0.089 & 0.003 & 0.149 & 0.120 & $2.730 * * *$ \\
\hline under15 & -0.007 & -0.049 & 0.497 & $1.875^{*}$ & -0.001 & -0.006 & -0.003 & -0.016 & 0.647 & $1.904 *$ \\
\hline over65 & -0.025 & -0.185 & 1.020 & $4.174 * * *$ & 0.001 & 0.009 & 0.024 & 0.158 & 1.327 & $4.337 * * *$ \\
\hline white & -0.019 & -1.094 & -0.198 & $-6.112 * * *$ & -0.027 & -1.552 & -0.040 & $-2.028 * *$ & -0.256 & $-6.158 * * *$ \\
\hline debt & -0.021 & -0.011 & -3.519 & -0.956 & -0.704 & -0.352 & -1.442 & -0.620 & -4.726 & -1.010 \\
\hline healthcare & -1.753 & $-1.818 *$ & 3.060 & $1.732 *$ & -1.606 & -1.672 & -2.261 & $-2.024 * *$ & 2.928 & 1.273 \\
\hline $\mathrm{W}^{*}$ nominate & -0.033 & -1.608 & -0.119 & $-3.138 * * *$ & -0.029 & -1.394 & -0.029 & -1.263 & -0.155 & $-3.174 * * *$ \\
\hline $\mathrm{W}^{*}$ citizen & 0.036 & 1.207 & -0.029 & -0.530 & 0.018 & 0.600 & 0.003 & 0.093 & -0.040 & -0.561 \\
\hline $\mathrm{W}^{*}$ under15 & 0.034 & 0.217 & -0.384 & -1.347 & 0.048 & 0.310 & 0.069 & 0.388 & -0.504 & -1.367 \\
\hline $\mathrm{W}^{*}$ white & 0.047 & 1.457 & 0.186 & $3.165 * * *$ & 0.054 & $1.703 *$ & 0.070 & $1.862 *$ & 0.235 & $3.233 * * *$ \\
\hline $\mathrm{W}^{*}$ debt & 5.962 & 1.606 & 28.528 & $4.205^{* * *}$ & 5.856 & 1.585 & 6.610 & 1.597 & 36.235 & $4.210 * * *$ \\
\hline $\mathrm{W}^{*}$ healthcare & 16.278 & $9.118 * * *$ & -6.424 & $-1.897^{*}$ & 13.660 & $7.358 * * *$ & 13.058 & $6.314 * * *$ & -9.438 & $-2.164 * *$ \\
\hline$\rho$ & & & & & & & 0.131 & $9.193 * * *$ & 0.221 & $7.911 * * *$ \\
\hline $\mathrm{N}$ & 2448 & & 2448 & & 2448 & & 2448 & & 2448 & \\
\hline R-squared & 0.924 & & 0.744 & & 0.925 & & 0.927 & & 0.750 & \\
\hline
\end{tabular}

The dependent variable in all model specifications is U.S. state level cigarette excise tax per pack, in cents. 
Table 10 Space-Time Estimations of U.S. State Cigarette Tax Rates

\begin{tabular}{cccccc} 
Variables & mean & 0.01 & 0.01 & 0.05 & 0.05 \\
\hline phi & 0.7414 & 0.7124 & 0.7679 & 0.7197 & 0.7599 \\
rho & 0.3484 & 0.2889 & 0.4042 & 0.3008 & 0.395 \\
theta & -0.1744 & -0.2266 & -0.1099 & -0.2175 & -0.1278 \\
-rho*phi & -0.2583 & -0.3008 & -0.2148 & -0.2937 & -0.2234 \\
$\sigma_{\varepsilon}^{-2}$ & 53.5099 & 49.5831 & 57.6039 & 50.6001 & 56.6581 \\
$\sigma_{\mu}^{-2}$ & 0.3332 & 0.0051 & 1.6252 & 0.0104 & 1.2151
\end{tabular}


Table 11 Space-Time Direct Effect Estimates

Nominate

\begin{tabular}{ccccccc}
\hline $\begin{array}{c}\text { Horizon } \\
\mathrm{T}\end{array}$ & $\begin{array}{c}\text { Cumulative } \\
\text { Effects }\end{array}$ & $\begin{array}{c}\text { Single Period } \\
\text { Effect (Mean) }\end{array}$ & $\begin{array}{c}\text { lower } \\
0.01\end{array}$ & $\begin{array}{c}\text { upper } \\
0.01\end{array}$ & $\begin{array}{c}\text { lower } \\
0.05\end{array}$ & $\begin{array}{c}\text { upper } \\
0.05\end{array}$ \\
\hline 0 & 0.02 & 0.02 & 0.00 & 0.04 & 0.00 & 0.04 \\
1 & 0.04 & 0.02 & 0.00 & 0.03 & 0.00 & 0.03 \\
2 & 0.05 & 0.01 & 0.00 & 0.02 & 0.00 & 0.02 \\
3 & 0.06 & 0.01 & 0.00 & 0.02 & 0.00 & 0.02 \\
4 & 0.06 & 0.01 & 0.00 & 0.02 & 0.00 & 0.01 \\
5 & 0.07 & 0.00 & 0.00 & 0.01 & 0.00 & 0.01 \\
10 & 0.08 & 0.00 & 0.00 & 0.00 & 0.00 & 0.00 \\
15 & 0.08 & 0.00 & 0.00 & 0.00 & 0.00 & 0.00 \\
20 & 0.08 & 0.00 & 0.00 & 0.00 & 0.00 & 0.00 \\
25 & 0.08 & 0.00 & 0.00 & 0.00 & 0.00 & 0.00 \\
30 & 0.08 & 0.00 & 0.00 & 0.00 & 0.00 & 0.00 \\
35 & 0.08 & 0.00 & 0.00 & 0.00 & 0.00 & 0.00 \\
40 & 0.08 & 0.00 & 0.00 & 0.00 & 0.00 & 0.00 \\
45 & 0.08 & 0.00 & 0.00 & 0.00 & 0.00 & 0.00 \\
46 & 0.08 & 0.00 & 0.00 & 0.00 & 0.00 & 0.00 \\
47 & 0.08 & 0.00 & 0.00 & 0.00 & 0.00 & 0.00
\end{tabular}

Citizen

\begin{tabular}{ccccccc}
\hline $\begin{array}{c}\text { Horizon } \\
\mathrm{T}\end{array}$ & $\begin{array}{c}\text { Cumulative } \\
\text { Effects }\end{array}$ & $\begin{array}{c}\text { Single Period } \\
\text { Effect (Mean) }\end{array}$ & $\begin{array}{c}\text { lower } \\
0.01\end{array}$ & $\begin{array}{c}\text { upper } \\
0.01\end{array}$ & $\begin{array}{c}\text { lower } \\
0.05\end{array}$ & $\begin{array}{c}\text { upper } \\
0.05\end{array}$ \\
\hline 0 & 0.00 & 0.00 & -0.04 & 0.05 & -0.03 & 0.04 \\
1 & 0.01 & 0.00 & -0.03 & 0.03 & -0.02 & 0.03 \\
2 & 0.01 & 0.00 & -0.02 & 0.02 & -0.02 & 0.02 \\
3 & 0.01 & 0.00 & -0.02 & 0.02 & -0.01 & 0.02 \\
4 & 0.01 & 0.00 & -0.01 & 0.01 & -0.01 & 0.01 \\
5 & 0.01 & 0.00 & -0.01 & 0.01 & -0.01 & 0.01 \\
10 & 0.01 & 0.00 & 0.00 & 0.00 & 0.00 & 0.00 \\
15 & 0.01 & 0.00 & 0.00 & 0.00 & 0.00 & 0.00 \\
20 & 0.01 & 0.00 & 0.00 & 0.00 & 0.00 & 0.00 \\
25 & 0.01 & 0.00 & 0.00 & 0.00 & 0.00 & 0.00 \\
30 & 0.01 & 0.00 & 0.00 & 0.00 & 0.00 & 0.00 \\
35 & 0.01 & 0.00 & 0.00 & 0.00 & 0.00 & 0.00 \\
40 & 0.01 & 0.00 & 0.00 & 0.00 & 0.00 & 0.00 \\
45 & 0.01 & 0.00 & 0.00 & 0.00 & 0.00 & 0.00 \\
46 & 0.01 & 0.00 & 0.00 & 0.00 & 0.00 & 0.00 \\
47 & 0.01 & 0.00 & 0.00 & 0.00 & 0.00 & 0.00
\end{tabular}


Under15

\begin{tabular}{ccccccc}
\hline $\begin{array}{c}\text { Horizon } \\
\mathrm{T}\end{array}$ & $\begin{array}{c}\text { Cumulative } \\
\text { Effects }\end{array}$ & $\begin{array}{c}\text { Single Period } \\
\text { Effect (Mean) }\end{array}$ & $\begin{array}{c}\text { lower } \\
0.01\end{array}$ & $\begin{array}{c}\text { upper } \\
0.01\end{array}$ & $\begin{array}{c}\text { lower } \\
0.05\end{array}$ & $\begin{array}{c}\text { upper } \\
0.05\end{array}$ \\
\hline 0 & 0.16 & 0.16 & -0.17 & 0.56 & -0.10 & 0.47 \\
1 & 0.27 & 0.11 & -0.13 & 0.41 & -0.07 & 0.34 \\
2 & 0.35 & 0.08 & -0.10 & 0.30 & -0.06 & 0.25 \\
3 & 0.41 & 0.06 & -0.07 & 0.22 & -0.04 & 0.18 \\
4 & 0.46 & 0.04 & -0.06 & 0.16 & -0.03 & 0.13 \\
5 & 0.49 & 0.03 & -0.04 & 0.12 & -0.02 & 0.10 \\
10 & 0.56 & 0.01 & -0.01 & 0.03 & -0.01 & 0.02 \\
15 & 0.57 & 0.00 & 0.00 & 0.01 & 0.00 & 0.00 \\
20 & 0.57 & 0.00 & 0.00 & 0.00 & 0.00 & 0.00 \\
25 & 0.57 & 0.00 & 0.00 & 0.00 & 0.00 & 0.00 \\
30 & 0.57 & 0.00 & 0.00 & 0.00 & 0.00 & 0.00 \\
35 & 0.57 & 0.00 & 0.00 & 0.00 & 0.00 & 0.00 \\
40 & 0.57 & 0.00 & 0.00 & 0.00 & 0.00 & 0.00 \\
45 & 0.57 & 0.00 & 0.00 & 0.00 & 0.00 & 0.00 \\
46 & 0.57 & 0.00 & 0.00 & 0.00 & 0.00 & 0.00 \\
47 & 0.57 & 0.00 & 0.00 & 0.00 & 0.00 & 0.00
\end{tabular}

Over65

\begin{tabular}{ccccccc}
\hline $\begin{array}{c}\text { Horizon } \\
\mathrm{T}\end{array}$ & $\begin{array}{c}\text { Cumulative } \\
\text { Effects }\end{array}$ & $\begin{array}{c}\text { Single Period } \\
\text { Effect (Mean) }\end{array}$ & $\begin{array}{c}\text { lower } \\
0.01\end{array}$ & $\begin{array}{c}\text { upper } \\
0.01\end{array}$ & $\begin{array}{c}\text { lower } \\
0.05\end{array}$ & $\begin{array}{c}\text { upper } \\
0.05\end{array}$ \\
\hline 0 & 0.37 & 0.37 & 0.04 & 0.69 & 0.11 & 0.62 \\
1 & 0.65 & 0.27 & 0.03 & 0.50 & 0.08 & 0.46 \\
2 & 0.84 & 0.20 & 0.02 & 0.38 & 0.06 & 0.33 \\
3 & 0.99 & 0.15 & 0.01 & 0.28 & 0.04 & 0.25 \\
4 & 1.10 & 0.11 & 0.01 & 0.22 & 0.03 & 0.18 \\
5 & 1.17 & 0.08 & 0.01 & 0.16 & 0.02 & 0.13 \\
10 & 1.35 & 0.02 & 0.00 & 0.04 & 0.00 & 0.03 \\
15 & 1.38 & 0.00 & 0.00 & 0.01 & 0.00 & 0.01 \\
20 & 1.39 & 0.00 & 0.00 & 0.00 & 0.00 & 0.00 \\
25 & 1.39 & 0.00 & 0.00 & 0.00 & 0.00 & 0.00 \\
30 & 1.40 & 0.00 & 0.00 & 0.00 & 0.00 & 0.00 \\
35 & 1.40 & 0.00 & 0.00 & 0.00 & 0.00 & 0.00 \\
40 & 1.40 & 0.00 & 0.00 & 0.00 & 0.00 & 0.00 \\
45 & 1.40 & 0.00 & 0.00 & 0.00 & 0.00 & 0.00 \\
46 & 1.40 & 0.00 & 0.00 & 0.00 & 0.00 & 0.00 \\
47 & 1.40 & 0.00 & 0.00 & 0.00 & 0.00 & 0.00
\end{tabular}


White

\begin{tabular}{ccccccc}
\hline Horizon & Cumulative & Single Period & lower & upper & lower & upper \\
$\mathrm{T}$ & Effects & Effect (Mean) & 0.01 & 0.01 & 0.05 & 0.05 \\
\hline 0 & -0.05 & -0.05 & -0.11 & 0.00 & -0.09 & -0.02 \\
1 & -0.08 & -0.04 & -0.08 & 0.00 & -0.06 & -0.01 \\
2 & -0.11 & -0.03 & -0.06 & 0.00 & -0.05 & -0.01 \\
3 & -0.13 & -0.02 & -0.04 & 0.00 & -0.03 & -0.01 \\
4 & -0.15 & -0.01 & -0.03 & 0.00 & -0.03 & 0.00 \\
5 & -0.16 & -0.01 & -0.02 & 0.00 & -0.02 & 0.00 \\
10 & -0.18 & 0.00 & -0.01 & 0.00 & -0.01 & 0.00 \\
15 & -0.19 & 0.00 & 0.00 & 0.00 & 0.00 & 0.00 \\
20 & -0.19 & 0.00 & 0.00 & 0.00 & 0.00 & 0.00 \\
25 & -0.19 & 0.00 & 0.00 & 0.00 & 0.00 & 0.00 \\
30 & -0.19 & 0.00 & 0.00 & 0.00 & 0.00 & 0.00 \\
35 & -0.19 & 0.00 & 0.00 & 0.00 & 0.00 & 0.00 \\
40 & -0.19 & 0.00 & 0.00 & 0.00 & 0.00 & 0.00 \\
45 & -0.19 & 0.00 & 0.00 & 0.00 & 0.00 & 0.00 \\
46 & -0.19 & 0.00 & 0.00 & 0.00 & 0.00 & 0.00 \\
47 & -0.19 & 0.00 & 0.00 & 0.00 & 0.00 & 0.00
\end{tabular}

Interest

\begin{tabular}{ccccccc}
\hline $\begin{array}{c}\text { Horizon } \\
\mathrm{T}\end{array}$ & $\begin{array}{c}\text { Cumulative } \\
\text { Effects }\end{array}$ & $\begin{array}{c}\text { Single Period } \\
\text { Effect (Mean) }\end{array}$ & $\begin{array}{c}\text { lower } \\
0.01\end{array}$ & $\begin{array}{c}\text { upper } \\
0.01\end{array}$ & $\begin{array}{c}\text { lower } \\
0.05\end{array}$ & $\begin{array}{c}\text { upper } \\
0.05\end{array}$ \\
\hline 0 & 5.59 & 5.59 & 0.80 & 10.53 & 2.12 & 8.95 \\
1 & 9.80 & 4.21 & 0.66 & 7.66 & 1.49 & 6.70 \\
2 & 12.98 & 3.18 & 0.48 & 5.59 & 1.15 & 4.98 \\
3 & 15.38 & 2.41 & 0.36 & 4.18 & 0.89 & 3.74 \\
4 & 17.22 & 1.83 & 0.25 & 3.20 & 0.65 & 2.84 \\
5 & 18.62 & 1.40 & 0.16 & 2.47 & 0.46 & 2.17 \\
10 & 22.09 & 0.40 & 0.02 & 0.72 & 0.11 & 0.65 \\
15 & 23.14 & 0.13 & -0.02 & 0.26 & 0.02 & 0.23 \\
20 & 23.50 & 0.05 & -0.02 & 0.11 & 0.00 & 0.10 \\
25 & 23.64 & 0.02 & -0.01 & 0.05 & 0.00 & 0.04 \\
30 & 23.70 & 0.01 & -0.01 & 0.03 & 0.00 & 0.02 \\
35 & 23.73 & 0.00 & 0.00 & 0.01 & 0.00 & 0.01 \\
40 & 23.74 & 0.00 & 0.00 & 0.01 & 0.00 & 0.01 \\
45 & 23.74 & 0.00 & 0.00 & 0.00 & 0.00 & 0.00 \\
46 & 23.74 & 0.00 & 0.00 & 0.00 & 0.00 & 0.00 \\
47 & 23.75 & 0.00 & 0.00 & 0.00 & 0.00 & 0.00
\end{tabular}


Healthcare

\begin{tabular}{ccccccc}
\hline Horizon & Cumulative & Single Period & lower & upper & lower & upper \\
$\mathrm{T}$ & Effects & Effect (Mean) & 0.01 & 0.01 & 0.05 & 0.05 \\
\hline 0 & -3.34 & -3.34 & -5.81 & -1.12 & -5.02 & -1.70 \\
1 & -5.84 & -2.50 & -4.44 & -0.82 & -3.75 & -1.26 \\
2 & -7.73 & -1.89 & -3.40 & -0.58 & -2.82 & -0.94 \\
3 & -9.15 & -1.43 & -2.61 & -0.44 & -2.10 & -0.73 \\
4 & -10.24 & -1.08 & -2.01 & -0.32 & -1.62 & -0.53 \\
5 & -11.06 & -0.83 & -1.56 & -0.22 & -1.26 & -0.40 \\
10 & -13.10 & -0.23 & -0.50 & -0.04 & -0.40 & -0.09 \\
15 & -13.71 & -0.08 & -0.20 & 0.00 & -0.16 & -0.02 \\
20 & -13.92 & -0.03 & -0.09 & 0.00 & -0.07 & 0.00 \\
25 & -14.01 & -0.01 & -0.05 & 0.00 & -0.03 & 0.00 \\
30 & -14.04 & -0.01 & -0.03 & 0.00 & -0.02 & 0.00 \\
35 & -14.06 & 0.00 & -0.01 & 0.00 & -0.01 & 0.00 \\
40 & -14.07 & 0.00 & -0.01 & 0.00 & -0.01 & 0.00 \\
45 & -14.07 & 0.00 & 0.00 & 0.00 & 0.00 & 0.00 \\
46 & -14.07 & 0.00 & 0.00 & 0.00 & 0.00 & 0.00 \\
47 & -14.07 & 0.00 & 0.00 & 0.00 & 0.00 & 0.00
\end{tabular}


Table 12 Space-Time Indirect Effect Estimates

Nominate

\begin{tabular}{ccccccc}
\hline $\begin{array}{c}\text { Horizon } \\
\mathrm{T}\end{array}$ & $\begin{array}{c}\text { Cumulative } \\
\text { Effects }\end{array}$ & $\begin{array}{c}\text { Single Period } \\
\text { Effect (Mean) }\end{array}$ & $\begin{array}{c}\text { lower } \\
0.01\end{array}$ & $\begin{array}{c}\text { upper } \\
0.01\end{array}$ & $\begin{array}{c}\text { lower } \\
0.05\end{array}$ & $\begin{array}{c}\text { upper } \\
0.05\end{array}$ \\
\hline 0 & -0.01 & -0.01 & -0.09 & 0.06 & -0.07 & 0.05 \\
1 & -0.01 & 0.00 & -0.07 & 0.06 & -0.06 & 0.05 \\
2 & -0.01 & 0.00 & -0.06 & 0.05 & -0.05 & 0.04 \\
3 & -0.01 & 0.00 & -0.05 & 0.05 & -0.04 & 0.04 \\
4 & -0.01 & 0.00 & -0.04 & 0.04 & -0.03 & 0.04 \\
5 & -0.01 & 0.00 & -0.03 & 0.04 & -0.03 & 0.03 \\
10 & 0.00 & 0.00 & -0.02 & 0.03 & -0.01 & 0.02 \\
15 & 0.01 & 0.00 & -0.01 & 0.02 & -0.01 & 0.01 \\
20 & 0.02 & 0.00 & -0.01 & 0.01 & 0.00 & 0.01 \\
25 & 0.02 & 0.00 & 0.00 & 0.01 & 0.00 & 0.00 \\
30 & 0.03 & 0.00 & 0.00 & 0.00 & 0.00 & 0.00 \\
35 & 0.03 & 0.00 & 0.00 & 0.00 & 0.00 & 0.00 \\
40 & 0.03 & 0.00 & 0.00 & 0.00 & 0.00 & 0.00 \\
45 & 0.03 & 0.00 & 0.00 & 0.00 & 0.00 & 0.00 \\
46 & 0.03 & 0.00 & 0.00 & 0.00 & 0.00 & 0.00 \\
47 & 0.03 & 0.00 & 0.00 & 0.00 & 0.00 & 0.00
\end{tabular}

\section{Citizen}

\begin{tabular}{ccccccc}
\hline $\begin{array}{c}\text { Horizon } \\
\mathrm{T}\end{array}$ & $\begin{array}{c}\text { Cumulative } \\
\text { Effects }\end{array}$ & $\begin{array}{c}\text { Single Period } \\
\text { Effect (Mean) }\end{array}$ & $\begin{array}{c}\text { lower } \\
0.01\end{array}$ & $\begin{array}{c}\text { upper } \\
0.01\end{array}$ & $\begin{array}{c}\text { lower } \\
0.05\end{array}$ & $\begin{array}{c}\text { upper } \\
0.05\end{array}$ \\
\hline 0 & -0.02 & -0.02 & -0.14 & 0.11 & -0.11 & 0.06 \\
1 & -0.04 & -0.02 & -0.13 & 0.09 & -0.09 & 0.05 \\
2 & -0.05 & -0.01 & -0.11 & 0.07 & -0.08 & 0.04 \\
3 & -0.06 & -0.01 & -0.10 & 0.06 & -0.07 & 0.04 \\
4 & -0.07 & -0.01 & -0.08 & 0.05 & -0.06 & 0.03 \\
5 & -0.08 & -0.01 & -0.07 & 0.04 & -0.05 & 0.03 \\
10 & -0.11 & 0.00 & -0.04 & 0.02 & -0.03 & 0.02 \\
15 & -0.13 & 0.00 & -0.02 & 0.01 & -0.02 & 0.01 \\
20 & -0.13 & 0.00 & -0.01 & 0.01 & -0.01 & 0.00 \\
25 & -0.14 & 0.00 & -0.01 & 0.00 & -0.01 & 0.00 \\
30 & -0.14 & 0.00 & -0.01 & 0.00 & 0.00 & 0.00 \\
35 & -0.14 & 0.00 & 0.00 & 0.00 & 0.00 & 0.00 \\
40 & -0.14 & 0.00 & 0.00 & 0.00 & 0.00 & 0.00 \\
45 & -0.15 & 0.00 & 0.00 & 0.00 & 0.00 & 0.00 \\
46 & -0.15 & 0.00 & 0.00 & 0.00 & 0.00 & 0.00 \\
47 & -0.15 & 0.00 & 0.00 & 0.00 & 0.00 & 0.00
\end{tabular}


Under15

\begin{tabular}{ccccccc}
\hline Horizon & Cumulative & Single Period & lower & upper & lower & upper \\
$\mathrm{T}$ & Effects & Effect (Mean) & 0.01 & 0.01 & 0.05 & 0.05 \\
\hline 0 & -0.22 & -0.22 & -0.71 & 0.17 & -0.59 & 0.11 \\
1 & -0.39 & -0.17 & -0.57 & 0.14 & -0.45 & 0.08 \\
2 & -0.52 & -0.13 & -0.47 & 0.12 & -0.34 & 0.06 \\
3 & -0.62 & -0.10 & -0.38 & 0.10 & -0.27 & 0.05 \\
4 & -0.70 & -0.08 & -0.30 & 0.09 & -0.22 & 0.04 \\
5 & -0.77 & -0.06 & -0.24 & 0.07 & -0.18 & 0.04 \\
10 & -0.94 & -0.02 & -0.09 & 0.04 & -0.08 & 0.03 \\
15 & -1.01 & -0.01 & -0.05 & 0.02 & -0.04 & 0.02 \\
20 & -1.04 & 0.00 & -0.02 & 0.01 & -0.02 & 0.01 \\
25 & -1.06 & 0.00 & -0.01 & 0.01 & -0.01 & 0.00 \\
30 & -1.06 & 0.00 & -0.01 & 0.00 & -0.01 & 0.00 \\
35 & -1.07 & 0.00 & -0.01 & 0.00 & 0.00 & 0.00 \\
40 & -1.07 & 0.00 & 0.00 & 0.00 & 0.00 & 0.00 \\
45 & -1.07 & 0.00 & 0.00 & 0.00 & 0.00 & 0.00 \\
46 & -1.07 & 0.00 & 0.00 & 0.00 & 0.00 & 0.00 \\
47 & -1.07 & 0.00 & 0.00 & 0.00 & 0.00 & 0.00
\end{tabular}

\section{Over65}

\begin{tabular}{ccccccc}
\hline $\begin{array}{c}\text { Horizon } \\
\mathrm{T}\end{array}$ & $\begin{array}{c}\text { Cumulative } \\
\text { Effects }\end{array}$ & $\begin{array}{c}\text { Single Period } \\
\text { Effect (Mean) }\end{array}$ & $\begin{array}{c}\text { lower } \\
0.01\end{array}$ & $\begin{array}{c}\text { upper } \\
0.01\end{array}$ & $\begin{array}{c}\text { lower } \\
0.05\end{array}$ & $\begin{array}{c}\text { upper } \\
0.05\end{array}$ \\
\hline 0 & -0.42 & -0.42 & -1.03 & 0.14 & -0.91 & 0.05 \\
1 & -0.72 & -0.31 & -0.83 & 0.16 & -0.73 & 0.08 \\
2 & -0.95 & -0.23 & -0.67 & 0.18 & -0.58 & 0.10 \\
3 & -1.13 & -0.17 & -0.55 & 0.19 & -0.48 & 0.10 \\
4 & -1.26 & -0.13 & -0.46 & 0.18 & -0.39 & 0.10 \\
5 & -1.36 & -0.10 & -0.38 & 0.18 & -0.33 & 0.10 \\
10 & -1.60 & -0.03 & -0.18 & 0.13 & -0.15 & 0.08 \\
15 & -1.68 & -0.01 & -0.10 & 0.09 & -0.08 & 0.05 \\
20 & -1.71 & 0.00 & -0.06 & 0.05 & -0.04 & 0.03 \\
25 & -1.72 & 0.00 & -0.04 & 0.03 & -0.02 & 0.02 \\
30 & -1.73 & 0.00 & -0.02 & 0.02 & -0.01 & 0.01 \\
35 & -1.73 & 0.00 & -0.01 & 0.01 & -0.01 & 0.01 \\
40 & -1.73 & 0.00 & -0.01 & 0.01 & 0.00 & 0.00 \\
45 & -1.73 & 0.00 & -0.01 & 0.00 & 0.00 & 0.00 \\
46 & -1.73 & 0.00 & -0.01 & 0.00 & 0.00 & 0.00 \\
47 & -1.73 & 0.00 & 0.00 & 0.00 & 0.00 & 0.00
\end{tabular}


White

\begin{tabular}{ccccccc}
\hline $\begin{array}{c}\text { Horizon } \\
\mathrm{T}\end{array}$ & $\begin{array}{c}\text { Cumulative } \\
\text { Effects }\end{array}$ & $\begin{array}{c}\text { Single Period } \\
\text { Effect (Mean) }\end{array}$ & $\begin{array}{c}\text { lower } \\
0.01\end{array}$ & $\begin{array}{c}\text { upper } \\
0.01\end{array}$ & $\begin{array}{c}\text { lower } \\
0.05\end{array}$ & $\begin{array}{c}\text { upper } \\
0.05\end{array}$ \\
\hline 0 & 0.04 & 0.04 & -0.07 & 0.16 & -0.06 & 0.13 \\
1 & 0.06 & 0.02 & -0.07 & 0.13 & -0.06 & 0.10 \\
2 & 0.08 & 0.02 & -0.06 & 0.11 & -0.05 & 0.09 \\
3 & 0.09 & 0.01 & -0.06 & 0.09 & -0.05 & 0.07 \\
4 & 0.10 & 0.01 & -0.06 & 0.08 & -0.05 & 0.06 \\
5 & 0.10 & 0.00 & -0.05 & 0.06 & -0.04 & 0.05 \\
10 & 0.10 & 0.00 & -0.03 & 0.03 & -0.03 & 0.02 \\
15 & 0.10 & 0.00 & -0.02 & 0.02 & -0.02 & 0.01 \\
20 & 0.09 & 0.00 & -0.01 & 0.01 & -0.01 & 0.01 \\
25 & 0.09 & 0.00 & -0.01 & 0.01 & 0.00 & 0.00 \\
30 & 0.09 & 0.00 & 0.00 & 0.00 & 0.00 & 0.00 \\
35 & 0.09 & 0.00 & 0.00 & 0.00 & 0.00 & 0.00 \\
40 & 0.09 & 0.00 & 0.00 & 0.00 & 0.00 & 0.00 \\
45 & 0.09 & 0.00 & 0.00 & 0.00 & 0.00 & 0.00 \\
46 & 0.09 & 0.00 & 0.00 & 0.00 & 0.00 & 0.00 \\
47 & 0.09 & 0.00 & 0.00 & 0.00 & 0.00 & 0.00
\end{tabular}

Interest

\begin{tabular}{ccccccc}
\hline $\begin{array}{c}\text { Horizon } \\
\mathrm{T}\end{array}$ & $\begin{array}{c}\text { Cumulative } \\
\text { Effects }\end{array}$ & $\begin{array}{c}\text { Single Period } \\
\text { Effect (Mean) }\end{array}$ & $\begin{array}{c}\text { lower } \\
0.01\end{array}$ & $\begin{array}{c}\text { upper } \\
0.01\end{array}$ & $\begin{array}{c}\text { lower } \\
0.05\end{array}$ & $\begin{array}{c}\text { upper } \\
0.05\end{array}$ \\
\hline 0 & 2.91 & 2.91 & -12.18 & 14.78 & -7.01 & 12.19 \\
1 & 6.11 & 3.20 & -10.24 & 13.12 & -5.23 & 11.22 \\
2 & 9.39 & 3.29 & -8.30 & 11.64 & -4.17 & 10.35 \\
3 & 12.62 & 3.23 & -6.76 & 10.24 & -3.09 & 9.41 \\
4 & 15.71 & 3.09 & -5.54 & 9.17 & -2.29 & 8.53 \\
5 & 18.60 & 2.89 & -4.56 & 8.01 & -1.72 & 7.65 \\
10 & 29.75 & 1.80 & -2.10 & 4.71 & -0.76 & 4.30 \\
15 & 36.21 & 1.01 & -1.18 & 2.76 & -0.39 & 2.42 \\
20 & 39.75 & 0.55 & -0.69 & 1.72 & -0.22 & 1.35 \\
25 & 41.66 & 0.29 & -0.41 & 1.11 & -0.13 & 0.83 \\
30 & 42.69 & 0.16 & -0.24 & 0.67 & -0.07 & 0.49 \\
35 & 43.24 & 0.09 & -0.14 & 0.40 & -0.04 & 0.31 \\
40 & 43.54 & 0.05 & -0.08 & 0.24 & -0.02 & 0.18 \\
45 & 43.70 & 0.03 & -0.05 & 0.14 & -0.01 & 0.11 \\
46 & 43.73 & 0.02 & -0.04 & 0.13 & -0.01 & 0.09 \\
47 & 43.75 & 0.02 & -0.04 & 0.12 & -0.01 & 0.08
\end{tabular}


Healthcare

\begin{tabular}{ccccccc}
\hline $\begin{array}{c}\text { Horizon } \\
\mathrm{T}\end{array}$ & $\begin{array}{c}\text { Cumulative } \\
\text { Effects }\end{array}$ & $\begin{array}{c}\text { Single Period } \\
\text { Effect (Mean) }\end{array}$ & $\begin{array}{c}\text { lower } \\
0.01\end{array}$ & upper & lower & upper \\
\hline 0 & -0.98 & -0.98 & -7.29 & 5.00 & -5.79 & 3.97 \\
1 & -2.27 & -1.29 & -6.84 & 3.70 & -5.64 & 2.93 \\
2 & -3.73 & -1.46 & -6.37 & 2.80 & -5.20 & 2.23 \\
3 & -5.25 & -1.52 & -5.89 & 2.19 & -4.95 & 1.78 \\
4 & -6.75 & -1.51 & -5.56 & 1.73 & -4.67 & 1.38 \\
5 & -8.21 & -1.46 & -5.28 & 1.37 & -4.29 & 1.08 \\
10 & -14.13 & -0.99 & -3.61 & 0.49 & -2.81 & 0.33 \\
15 & -17.78 & -0.58 & -2.35 & 0.21 & -1.76 & 0.12 \\
20 & -19.87 & -0.33 & -1.52 & 0.09 & -1.13 & 0.05 \\
25 & -21.04 & -0.18 & -0.97 & 0.04 & -0.71 & 0.02 \\
30 & -21.70 & -0.10 & -0.62 & 0.02 & -0.41 & 0.01 \\
35 & -22.07 & -0.06 & -0.39 & 0.01 & -0.25 & 0.01 \\
40 & -22.27 & -0.03 & -0.25 & 0.00 & -0.16 & 0.00 \\
45 & -22.39 & -0.02 & -0.16 & 0.00 & -0.10 & 0.00 \\
46 & -22.40 & -0.02 & -0.14 & 0.00 & -0.09 & 0.00 \\
47 & -22.42 & -0.01 & -0.13 & 0.00 & -0.08 & 0.00
\end{tabular}


Table 13 Total Effect Estimates

Nominate

\begin{tabular}{ccccccc}
\hline $\begin{array}{c}\text { Horizon } \\
\mathrm{T}\end{array}$ & $\begin{array}{c}\text { Cumulative } \\
\text { Effects }\end{array}$ & $\begin{array}{c}\text { Single Period } \\
\text { Effect (Mean) }\end{array}$ & $\begin{array}{c}\text { lower } \\
0.01\end{array}$ & $\begin{array}{c}\text { upper } \\
0.01\end{array}$ & $\begin{array}{c}\text { lower } \\
0.05\end{array}$ & $\begin{array}{c}\text { upper } \\
0.05\end{array}$ \\
\hline 0 & 0.013 & 0.013 & -0.073 & 0.099 & -0.054 & 0.072 \\
1 & 0.024 & 0.012 & -0.062 & 0.086 & -0.047 & 0.064 \\
2 & 0.035 & 0.010 & -0.053 & 0.075 & -0.041 & 0.057 \\
3 & 0.044 & 0.009 & -0.045 & 0.065 & -0.036 & 0.051 \\
4 & 0.052 & 0.008 & -0.040 & 0.056 & -0.031 & 0.045 \\
5 & 0.059 & 0.007 & -0.035 & 0.050 & -0.027 & 0.040 \\
10 & 0.084 & 0.004 & -0.018 & 0.029 & -0.014 & 0.022 \\
15 & 0.097 & 0.002 & -0.010 & 0.017 & -0.007 & 0.012 \\
20 & 0.105 & 0.001 & -0.006 & 0.010 & -0.004 & 0.007 \\
25 & 0.109 & 0.001 & -0.003 & 0.006 & -0.002 & 0.004 \\
30 & 0.112 & 0.000 & -0.002 & 0.004 & -0.001 & 0.003 \\
35 & 0.113 & 0.000 & -0.001 & 0.003 & -0.001 & 0.002 \\
40 & 0.114 & 0.000 & -0.001 & 0.002 & 0.000 & 0.001 \\
45 & 0.114 & 0.000 & 0.000 & 0.001 & 0.000 & 0.001 \\
46 & 0.114 & 0.000 & 0.000 & 0.001 & 0.000 & 0.001 \\
47 & 0.114 & 0.000 & 0.000 & 0.001 & 0.000 & 0.000
\end{tabular}

\section{Citizen}

\begin{tabular}{ccccccc}
\hline $\begin{array}{c}\text { Horizon } \\
\mathrm{T}\end{array}$ & Cumulative & Single Period & lower & upper & lower & upper \\
\hline 0 & -0.015 & -0.015 & -0.143 & 0.104 & -0.101 & 0.070 \\
1 & -0.028 & -0.013 & -0.124 & 0.089 & -0.091 & 0.061 \\
2 & -0.040 & -0.012 & -0.109 & 0.076 & -0.081 & 0.054 \\
3 & -0.050 & -0.010 & -0.097 & 0.066 & -0.073 & 0.047 \\
4 & -0.059 & -0.009 & -0.086 & 0.057 & -0.066 & 0.041 \\
5 & -0.068 & -0.008 & -0.077 & 0.049 & -0.060 & 0.036 \\
10 & -0.097 & -0.005 & -0.043 & 0.024 & -0.032 & 0.019 \\
15 & -0.114 & -0.003 & -0.024 & 0.014 & -0.018 & 0.009 \\
20 & -0.123 & -0.001 & -0.015 & 0.008 & -0.010 & 0.005 \\
25 & -0.128 & -0.001 & -0.009 & 0.004 & -0.006 & 0.003 \\
30 & -0.131 & 0.000 & -0.006 & 0.002 & -0.003 & 0.001 \\
35 & -0.133 & 0.000 & -0.004 & 0.001 & -0.002 & 0.001 \\
40 & -0.134 & 0.000 & -0.002 & 0.001 & -0.001 & 0.000 \\
45 & -0.134 & 0.000 & -0.002 & 0.000 & -0.001 & 0.000 \\
46 & -0.134 & 0.000 & -0.001 & 0.000 & -0.001 & 0.000 \\
47 & -0.134 & 0.000 & -0.001 & 0.000 & -0.001 & 0.000
\end{tabular}


Under15

\begin{tabular}{ccccccc}
\hline Horizon & Cumulative & Single Period & lower & upper & lower & upper \\
$\mathrm{T}$ & Effects & Effect (Mean) & 0.01 & 0.01 & 0.05 & 0.05 \\
\hline 0 & -0.064 & -0.064 & -0.347 & 0.171 & -0.260 & 0.129 \\
1 & -0.119 & -0.056 & -0.308 & 0.154 & -0.227 & 0.114 \\
2 & -0.168 & -0.048 & -0.263 & 0.140 & -0.199 & 0.099 \\
3 & -0.210 & -0.042 & -0.231 & 0.123 & -0.174 & 0.087 \\
4 & -0.246 & -0.037 & -0.202 & 0.106 & -0.152 & 0.078 \\
5 & -0.278 & -0.032 & -0.177 & 0.092 & -0.133 & 0.069 \\
10 & -0.386 & -0.016 & -0.091 & 0.046 & -0.070 & 0.036 \\
15 & -0.440 & -0.008 & -0.047 & 0.026 & -0.038 & 0.019 \\
20 & -0.468 & -0.004 & -0.026 & 0.015 & -0.022 & 0.011 \\
25 & -0.482 & -0.002 & -0.014 & 0.009 & -0.012 & 0.005 \\
30 & -0.490 & -0.001 & -0.009 & 0.005 & -0.007 & 0.003 \\
35 & -0.494 & -0.001 & -0.006 & 0.003 & -0.004 & 0.002 \\
40 & -0.496 & 0.000 & -0.004 & 0.002 & -0.002 & 0.001 \\
45 & -0.497 & 0.000 & -0.002 & 0.001 & -0.001 & 0.000 \\
46 & -0.497 & 0.000 & -0.002 & 0.001 & -0.001 & 0.000 \\
47 & -0.497 & 0.000 & -0.002 & 0.001 & -0.001 & 0.000
\end{tabular}

\section{Over65}

\begin{tabular}{ccccccc}
\hline $\begin{array}{c}\text { Horizon } \\
\mathrm{T}\end{array}$ & $\begin{array}{c}\text { Cumulative } \\
\text { Effects }\end{array}$ & $\begin{array}{c}\text { Single Period } \\
\text { Effect (Mean) }\end{array}$ & $\begin{array}{c}\text { lower } \\
0.01\end{array}$ & $\begin{array}{c}\text { upper } \\
0.01\end{array}$ & $\begin{array}{c}\text { lower } \\
0.05\end{array}$ & $\begin{array}{c}\text { upper } \\
0.05\end{array}$ \\
\hline 0 & -0.042 & -0.042 & -0.584 & 0.480 & -0.489 & 0.327 \\
1 & -0.078 & -0.036 & -0.513 & 0.422 & -0.431 & 0.291 \\
2 & -0.110 & -0.032 & -0.452 & 0.379 & -0.378 & 0.258 \\
3 & -0.138 & -0.028 & -0.397 & 0.337 & -0.337 & 0.229 \\
4 & -0.162 & -0.024 & -0.349 & 0.300 & -0.298 & 0.204 \\
5 & -0.184 & -0.021 & -0.307 & 0.266 & -0.260 & 0.181 \\
10 & -0.257 & -0.011 & -0.166 & 0.164 & -0.142 & 0.102 \\
15 & -0.295 & -0.006 & -0.100 & 0.097 & -0.081 & 0.055 \\
20 & -0.315 & -0.003 & -0.061 & 0.056 & -0.045 & 0.031 \\
25 & -0.326 & -0.002 & -0.039 & 0.030 & -0.025 & 0.017 \\
30 & -0.331 & -0.001 & -0.024 & 0.017 & -0.014 & 0.010 \\
35 & -0.334 & 0.000 & -0.015 & 0.011 & -0.008 & 0.006 \\
40 & -0.336 & 0.000 & -0.010 & 0.007 & -0.004 & 0.003 \\
45 & -0.337 & 0.000 & -0.006 & 0.004 & -0.003 & 0.002 \\
46 & -0.337 & 0.000 & -0.006 & 0.004 & -0.002 & 0.002 \\
47 & -0.337 & 0.000 & -0.005 & 0.003 & -0.002 & 0.002
\end{tabular}


White

\begin{tabular}{ccccccc}
\hline $\begin{array}{c}\text { Horizon } \\
\mathrm{T}\end{array}$ & Cumulative & Single Period & lower & upper & lower & upper \\
\hline 0 & Effects & Effect (Mean) & 0.01 & 0.01 & 0.05 & 0.05 \\
1 & -0.013 & -0.013 & -0.134 & 0.113 & -0.109 & 0.083 \\
2 & -0.023 & -0.011 & -0.118 & 0.099 & -0.099 & 0.072 \\
3 & -0.033 & -0.010 & -0.104 & 0.087 & -0.085 & 0.064 \\
4 & -0.042 & -0.008 & -0.091 & 0.076 & -0.075 & 0.056 \\
5 & -0.049 & -0.007 & -0.081 & 0.065 & -0.066 & 0.049 \\
10 & -0.055 & -0.007 & -0.073 & 0.056 & -0.058 & 0.044 \\
15 & -0.078 & -0.003 & -0.042 & 0.031 & -0.030 & 0.023 \\
20 & -0.090 & -0.002 & -0.025 & 0.017 & -0.017 & 0.012 \\
25 & -0.096 & -0.001 & -0.014 & 0.010 & -0.009 & 0.007 \\
30 & -0.099 & -0.001 & -0.008 & 0.005 & -0.005 & 0.003 \\
35 & -0.101 & 0.000 & -0.005 & 0.003 & -0.003 & 0.002 \\
40 & -0.102 & 0.000 & -0.003 & 0.002 & -0.002 & 0.001 \\
45 & -0.103 & 0.000 & -0.002 & 0.001 & -0.001 & 0.001 \\
46 & -0.103 & 0.000 & -0.001 & 0.001 & -0.001 & 0.000 \\
47 & -0.103 & 0.000 & -0.001 & 0.001 & -0.001 & 0.000 \\
& -0.103 & 0.000 & -0.001 & 0.001 & 0.000 & 0.000
\end{tabular}

Interest

\begin{tabular}{ccccccc}
\hline $\begin{array}{c}\text { Horizon } \\
\mathrm{T}\end{array}$ & $\begin{array}{c}\text { Cumulative } \\
\text { Effects }\end{array}$ & $\begin{array}{c}\text { Single Period } \\
\text { Effect (Mean) }\end{array}$ & $\begin{array}{c}\text { lower } \\
0.01\end{array}$ & $\begin{array}{c}\text { upper } \\
0.01\end{array}$ & $\begin{array}{c}\text { lower } \\
0.05\end{array}$ & $\begin{array}{c}\text { upper } \\
0.05\end{array}$ \\
\hline 0 & 8.500 & 8.500 & -7.613 & 20.843 & -1.963 & 19.061 \\
1 & 15.909 & 7.409 & -6.534 & 17.797 & -1.733 & 16.271 \\
2 & 22.370 & 6.462 & -5.609 & 15.214 & -1.531 & 14.121 \\
3 & 28.008 & 5.638 & -4.814 & 13.195 & -1.338 & 12.229 \\
4 & 32.929 & 4.921 & -4.132 & 11.468 & -1.184 & 10.764 \\
5 & 37.227 & 4.297 & -3.546 & 9.970 & -1.053 & 9.461 \\
10 & 51.838 & 2.197 & -2.044 & 5.191 & -0.584 & 4.944 \\
15 & 59.351 & 1.135 & -1.207 & 2.967 & -0.360 & 2.645 \\
20 & 63.253 & 0.592 & -0.713 & 1.833 & -0.220 & 1.446 \\
25 & 65.301 & 0.312 & -0.421 & 1.163 & -0.128 & 0.867 \\
30 & 66.386 & 0.166 & -0.249 & 0.696 & -0.073 & 0.516 \\
35 & 66.966 & 0.089 & -0.147 & 0.416 & -0.036 & 0.317 \\
40 & 67.279 & 0.048 & -0.087 & 0.249 & -0.017 & 0.181 \\
45 & 67.449 & 0.026 & -0.051 & 0.149 & -0.009 & 0.109 \\
46 & 67.472 & 0.023 & -0.046 & 0.135 & -0.008 & 0.098 \\
47 & 67.493 & 0.021 & -0.041 & 0.121 & -0.007 & 0.088
\end{tabular}


Healthcare

\begin{tabular}{ccccccc}
\hline Horizon & Cumulative & Single Period & lower & upper & lower & upper \\
$\mathrm{T}$ & Effects & Effect (Mean) & 0.01 & 0.01 & 0.05 & 0.05 \\
\hline 0 & -4.317 & -4.317 & -11.025 & 2.055 & -9.650 & 0.786 \\
1 & -8.115 & -3.798 & -9.799 & 1.752 & -8.291 & 0.684 \\
2 & -11.457 & -3.342 & -8.709 & 1.488 & -7.544 & 0.595 \\
3 & -14.400 & -2.942 & -7.885 & 1.262 & -6.813 & 0.518 \\
4 & -16.991 & -2.591 & -7.227 & 1.070 & -6.026 & 0.451 \\
5 & -19.274 & -2.283 & -6.624 & 0.907 & -5.297 & 0.392 \\
10 & -27.224 & -1.218 & -4.024 & 0.417 & -3.146 & 0.193 \\
15 & -31.487 & -0.656 & -2.546 & 0.188 & -1.927 & 0.096 \\
20 & -33.793 & -0.356 & -1.611 & 0.083 & -1.198 & 0.048 \\
25 & -35.051 & -0.195 & -1.019 & 0.038 & -0.745 & 0.024 \\
30 & -35.743 & -0.108 & -0.645 & 0.017 & -0.426 & 0.012 \\
35 & -36.127 & -0.060 & -0.408 & 0.008 & -0.264 & 0.006 \\
40 & -36.341 & -0.034 & -0.258 & 0.003 & -0.167 & 0.002 \\
45 & -36.461 & -0.019 & -0.163 & 0.002 & -0.104 & 0.001 \\
46 & -36.478 & -0.017 & -0.149 & 0.002 & -0.094 & 0.001 \\
47 & -36.493 & -0.015 & -0.136 & 0.001 & -0.085 & 0.001
\end{tabular}




\section{Chapter 4}

\section{Special Interest Group Influence on Tobacco Control Spending*}

\subsection{INTRODUCTION}

Why is there so much variation in tobacco control funding (TCF) across the United States? Scholars in economics, the health sciences, and political sciences and practitioners in public health organizations are deeply interested in finding an answer to this question. Yet while a large literature examines the impact of tobacco control programs and policies on tobacco use, only a handful of studies have addressed the causes of the disparity across states in funding these programs.

This note moves the literature on tobacco control in a new direction by considering the political economy factors that account for differences in TCF across states. We specifically focus on the role played by special interest groups in the formulation of state tobacco legislation. It is perhaps unsurprising that in terms of per capita TCF the top ten states produce no tobacco. Yet Tennessee, a major tobacco producer, had the lowest level of expenditures on tobacco control in 2007, with $\$ 0.13$ in TCF per person.

These statistics provide prima facie support for the idea that special interest groups in tobacco-producing states (specifically, tobacco lobbies) may have undue influence on the formulation of state tobacco legislation. Yet in order to understand whether tobacco production is systematically associated with different levels of TCF across states and over time, we put forth an econometric investigation. We observe a strong, negative conditional correlation between state-level tobacco production and state-level spending on tobacco control measures. We also provide evidence for a negative relationship between TCF and the level of campaign

\footnotetext{
${ }^{*}$ This chapter is based on Hoffer and Pellillo (2012)
} 
contributions from tobacco lobbies. These findings have strong implications for health organizations and policymakers who seek to influence tobacco control policies and programs in different states.

\subsection{TOBACCO CONTROL FUNDING}

\subsubsection{Funding Tobacco Control Funding}

Tobacco control spending was nonexistent in most U.S. states until1998. Where TCF existed, it was primarily funded through earmarked revenue generated from state-level increase in the cigarette excise tax rate. In 1998, the Master Settlement Agreement (MSA) between 46 state attorneys general and the four largest U.S. tobacco companies promised at least \$206 billion from the tobacco companies over a span of 25 years in exchange for recovery of state spending on tobacco-related medical costs and an exemption for tobacco companies against private tort liability due to harmful effects of tobacco consumption. ${ }^{8}$

The MSA totals to states were very wide-ranging, from $\$ 14.8$ million in Wyoming to \$974.2 million in Texas, and from about \$12 per capita in Utah to \$74 per capita in Mississippi. After the MSA and disbursement of payments to states, every state began funding tobacco control programs, though at substantially different rates. In 2001, the per capita TCF ranged from $\$ 0.10$ in Pennsylvania to $\$ 15.47$ in Maine. Despite their large settlement payments, states spent very little of their new revenue on tobacco control. In total during 2001, states spend six percent of their MSA revenue on tobacco control, using the other 94 percent as fungible revenue.

\subsubsection{State Spending on Tobacco Control}

How much states should spend on tobacco control is a question that has received a number of different answers, but the Center for Disease Control (CDC) publishes recommended minimum totals for states to spend on tobacco control. In 2007, the CDC "Best Practices" report

\footnotetext{
${ }^{8}$ The remaining four states all reached private settlements with the tobacco companies.
} 
suggested a range of $\$ 15$ to $\$ 20$ per capita for each state. The suggestions from the CDC, however, have been essentially ignored by almost every state. From 2000-2007, only Maine and Mississippi spent above the minimum levels suggested by the CDC, while ten states averages less than ten percent of the minimum CDC recommendations (Marlow, 2009).

The amount of spending was not the only item that varied widely by state. How, where, and why states spent on tobacco control was quite different. Wakefield and Chaloupka (2000) present case studies of a few of the more-tenured programs. California, Massachusetts, and Oregon had a very broad program focus, targeting adults, teenagers, and the protection of nonsmokers from the externality of external smoke. Arizona, on the other hand, focused their tobacco control efforts on decreasing consumption among preteens, teenagers, and pregnant women, while Florida targeted only teenage smokers.

At the state level, the largest areas of spending were in mass media messages, grants to local agencies, and school programs. Of the states studies in Wakefield and Chaloupka (2000), Arizona used the highest percentage of their TCF on mass media, at 54 percent, followed by Florida, at 37 percent. Massachusetts used the highest percentage of all states to transfer money to local agencies, at 43 percent of their total TCF spending. California spent more than any other state directly on school programs, 31 percent of their total TCF budget, while spending the lowest percentage of any state on mass media, 17 percent of their TCF. With these vast differences in approaches and goals to TCF, it should not be surprising that the measurable outcomes of these programs have been quite different.

\subsubsection{Outcomes of Tobacco Control Spending}

The literature on the effect of tobacco control spending on decreasing cigarette consumption has produced mixed results. Early studies focused on states like California and 
Massachusetts due to the longevity of their programs. Hu et al. (1995) found that state tobacco control spending decreased consumption in California. Wakefield and Chaloupka (2000) found evidence that tobacco control spending lead to policy changes that decreased cigarette consumption by teenagers.

Farelly et al. (2003) criticize many of the earlier works for focusing on trend analysis and too narrow of a focus of included states. Using all 50 U.S. states and an extended panel framework, Farelly et al. (2003) find that higher spending on tobacco control programs did decrease cigarette consumption. They also claim that if all U.S. states had spent the CDC recommended amounts on tobacco control, aggregate cigarette sales would have decreased by an additional nine percent. Taures et al. (2005) similarly concluded, looking at all U.S. states, that spending on tobacco control programs lowered youth smoking.

All of the previous studies, however, used data no more recent than the year 2000, when many states did not fund tobacco control programs whatsoever. Using a panel similar that that exploited in this study, Marlow (2009) investigates cigarette consumption and TCF from 20002007. He concludes that the empirical evidence does not support the CDC's claim that higher levels of spending on TCF leads to lower levels of cigarette consumption. The true effect, Marlow claims, is that additional spending on TCF has a zero effect on cigarette consumption.

Outside of cigarette consumption, TCF has claimed a number of results. Wakefield and Chaloupka (2000) describe that in both California and Massachusetts, there was an increase in the number of smoke-free workplaces and homes. Massachusetts also reported an increase in the number of smoke-free restaurants and public places. Where the data were available, Wakefiled and Chaloupka (2000) describe an overwhelming drop in the percentage of failed retailer 
compliance checks (e.g. selling to minors) in each state. The percentage failed retailer compliance checks in Florida fell from 48 percent to 8 percent over a four year span.

While the total impact of TCF remains undecided in the literature, the tobacco industry has put up a stiff resistance to state TCF. Wakefield and Chaloupka (2000) claim that the tobacco industry's heavily lobbying against TCF and was likely responsible for a one year delay in the implementation of tobacco control programs in Arizona.

\subsection{SPECIAL INTEREST GROUPS AND TOBACCO CONTROL FUNDING}

The role of political economy factors on tobacco-related policies has been investigated in a few studies in the literature on tobacco control, but not in any systematic empirical way. For instance, Giovino et al. (2009: 12) argue one of the impediments to reducing tobacco use is “... that some governments lack the political will to disseminate effective tobacco control strategies. This may occur because of political influence of the tobacco industry on lawmakers or because of concern about losing excise tax revenues as sales of various tobacco products decline.”

Surprisingly few papers have examined whether states with relatively high levels of tobacco production (or states that produce tobacco in general) have different tobacco legislation. Holcombe (1997) was the first to explore this linkage; he used the number of acres of tobacco farms per capita in a state as a proxy for the influence of special interest groups on state tobacco tax rates, finding a negative relationship between the two. Hoffer (2011) builds on this approach by employing a spatial econometric framework and an expanded data set, similarly finding a negative relationship between tobacco production and tobacco tax rates.

Based on these findings and the logic of the special interest group effect on policy formulation (see, among others, Tullock, 1967; Stigler, 1971; Kreuger, 1974; Peltzman, 1976; Becker, 1983; Ekelund and Tollison, 2001), there is reason to expect nontrivial relationships 
between tobacco special interest (tobacco production or tobacco lobbies' financial support for state legislative campaigns) and lower expenditures on tobacco control programs and policies. For instance, tobacco lobbies have a strong incentive to try to lower excise tax rates in a state (Hoffer, 2011). They also have the incentive to fight against policies or programs which will curb demand for their products (i.e. TCF). We should therefore also observe a negative relationship between TCF and the level of campaign contributions from tobacco lobbies to incumbents in and candidates for state legislative positions.

\subsection{DATA AND METHOD}

We employ state-level data from 2000 to 2007 for all U.S. states and Washington, D.C. to examine the impact of political economy factors on state TCF. Data sources and summary statistics are presented in Table 14. Our model is the following,

$$
\mathrm{TCS}_{\mathrm{st}}=\lambda_{\mathrm{t}}+\mathrm{TOBACCO}_{\mathrm{st}} \beta^{\prime}+\text { IDEOLOGY }_{\mathrm{st}}^{\prime} \gamma+\mathrm{X}_{\mathrm{st}}^{\prime} \delta+\varepsilon_{\mathrm{st}}
$$

where $\mathrm{TCS}_{\text {st }}$ is tobacco control spending per person in state $s$ at time $t . \mathrm{TOBACCO}_{\mathrm{st}}$ is the key explanatory variable of interest, which accounts for the tobacco special-interest effect using three different variables: tobacco production, the quantity of tobacco produced within the state; tobacco producer, a binary indicator for whether a state is a tobacco producer at time; and tobacco lobby, the total campaign contributions from the tobacco industry to state legislative members, smoothed over the election cycle. IDEOLOGY st is a vector of two ideological measures (citizen ideology and politician ideology), $\mathrm{X}_{\mathrm{st}}$ is a vector of control variables, $\lambda_{t}$ are time fixed effects, and $\varepsilon_{\text {st }}$ is a normally distributed error term. Here, $\beta, \gamma_{1}$ and $\gamma_{2}$ are the key parameters of interest, with the hypothesized coefficient signs $\beta<0, \gamma_{1}>0$, and $\gamma_{2}>0$. All relevant variables (including the dependent variable) are adjusted for inflation (2000 base year). 
We also control for a number of potentially important covariates that may influence state level TCF per person. The vector of control variables, $\mathrm{X}_{\mathrm{st}}$, includes tobacco tax revenue per capita because some states use the revenues from tobacco taxes to fund tobacco control policies and programs. We also control for the amount of funds a state receives from the 1998 MSA (and individual state settlements), as these funds are typically earmarked for spending on tobacco control as well. Lastly, we include information on the state beer tax, sales tax, the percentage of citizens under the age of 15 or over the age of 65 , the percentage of the population that lives in an urban area, the percent of the population that has at least a bachelor's degree, health spending per person, state spending per person, the percentage of GDP that is spent on state debt, and GDP per capita.

\subsection{RESULTS}

The results for the ordinary least squares regression of state tobacco control spending on the key explanatory variables and control variables are reported in Tables 15-17. We find that tobacco control spending is negatively related to the level of tobacco production, whether a state is a tobacco producer, and the level of campaign contributions from state tobacco lobbies. Specifically, from the second specification in Table 15, we find that a 10 million pound increase in state-level tobacco production is associated with a reduction in tobacco control spending by about $\$ 0.08$ per person across the entire panel. The magnitude of this effect is nontrivial considering that a $\$ 1,000$ decrease in GDP per person in a state has roughly the same impact on TCF.

Political ideology further to the left also resulted in higher levels of TCF. The ideology of citizens was positive and significant, while the coefficient on the ideology of a state's politicians was positive, but not statistically significant. 
The two primary funding sources of TCF, earmarked cigarette tax revenue and MSA revenue, were both positive and significant. While a dollar of revenue from the MSA translated into only $\$ 0.046$ of TCF, this amount was more than three times that of a dollar of revenue from the cigarette excise tax, which was turned into $\$ 0.014$ in TCF.

Table 16 introduces the tobacco producer dummy to explore the divide between tobacco producing and nonproducing states. On average, tobacco producing states spent $\$ 1.343$ less per capita on TCF than states that do not produce tobacco. This is a substantially large effect, as it would take more than $\$ 122$ of cigarette tax revenue per capita and more than $\$ 26$ of MSA revenue per person to offset the fact that a state is a tobacco producer.

Finally, Table 17 presents the model specification using campaign contributions from the tobacco industry to politicians running for state government offices. One thousand dollars in campaign contributions resulted in a state allocating $\$ 0.041$ less to TCF. This amount is slightly less than the additional amount of TCF spent from either a $\$ 1,000$ increase in GDP per person, $\$ 0.047$, or an extra dollar of MSA revenue, $\$ 0.049$.

Altogether, these conditional correlations are highly suggestive of a special interest group effect on state-level TCF. These results hold while controlling for other potential influences of TCF, including ideological factors, state revenue factors, and the level of funding from the Master Settlement Agreement (or other state-level legal agreements with tobacco companies).

\subsection{SPATIAL ECONOMETRIC ANALYSIS}

One potential critique of the regression model employed above deals with the strong assumptions of the ordinary least squares (OLS) regressor. By using the OLS regressor, we implicitly assume that observations of the dependent variable are independently determined. In practice, there are a number of unobservable factors at the state level that are likely to be 
systematically related over space. The use of a spatial econometric model may therefore help to ameliorate the potential bias and inefficiency that occur when using the OLS regressor. LeSage and Dominguez (2010) argue for the implementation of spatial econometric models in the literature of public economics, as policy decisions are commonly made with at least partial consideration of the policies of neighboring regions and potential policy responses of neighboring regions. In earlier chapters of this dissertation, OLS models were shown to substantially underestimate the effect of special interest when compared to spatial econometric models.

One of the greatest advantages from using a spatial econometric model is that estimates of both direct effects and indirect (spillover) effects can be estimated. In cases where local spillovers are more theoretically valid than global spillovers, Lesage and Pace (2011) describe the spatially lagged explanatory variables (SLX) model as an appropriate econometric estimation tool. This model involves spatially weighting the explanatory variables, but the dependent variable remains independent. ${ }^{9}$ As evinced by Figure 4, there is spatial clustering in observations of the dependent variable (tobacco control funding) and at least one independent variable (tobacco production). In order to properly account for spatial correlation in the data, we use model specification tests help

The data are analyzed following the procedure outlined by Florax, Folmer, and Rey (2003) using Lagrange Multiplier (LM) tests designed by Anselin, Bera, Floraz, and Yoon (1996). ${ }^{10}$ The first two tests, LM Lag and LM Error, test for the existence of spatial correlation in the dependent variable and the error term, respectively. If both tests are significantly different

\footnotetext{
${ }^{9}$ If the dependent variable does contain spatial correlation, the appropriate model would be the spatial Durbin model (SDM).

${ }^{10}$ The most comprehensive procedure for running these tests, to date, has been developed by Dr. Don Lacombe. MATLAB code for these tests are available on his website: http://community.wvu.edu/ dj1041/matlab.html.
} 
from zero, the second set of LM tests, LM Lag Robust and LM Error Robust, test for the existence of spatial correlation, similar to first stage tests, but account for the existence of spatial correlation in the alternative location (error term or dependent variable).

Table 18 presents the LM model specification tests. Column one presents the tests using OLS as the default specification. LM Lag and LM Error tests suggest the existence of spatial correlation in the dependent variable and error term, respectively, but LM Lag Robust and LM Error Robust are both insignificant, implying that there may be spatial error unobserved due to omitted spatially weighted independent variables. Therefore, column two presents the model specification tests from using the SLX model as the null hypotheses. Clearly, the results from these tests show that after including the vector of spatially weighted independent variables, there is no longer spatial dependence explained through the dependent variable or the error term.

Upon analyzing the model specification tests, a model that included spatially weighted independent variables was necessary. Therefore, in Table 19 we present a spatial Durbin model (SDM), which includes both spatially weighted dependent and independent variables and an SLX model. Implementing spatially weighted independent variables yields the SLX model,

$$
\begin{aligned}
& \text { TCS }_{\mathrm{it}}=\text { PRODUCER' }_{\mathrm{it}} \beta+\text { IDEOLOGY }_{\mathrm{it}}^{\prime} \gamma+\mathrm{X}_{\mathrm{it}}^{\prime} \delta+ \\
& \mathrm{W}\left[\text { PRODUCER }_{\mathrm{it}}^{\prime} \theta+\text { IDEOLOGY }_{\mathrm{it}}^{\prime} \psi+\mathrm{X}_{\mathrm{it}}^{\prime} \sigma\right]+\varepsilon_{\mathrm{it}},
\end{aligned}
$$

where $\mathrm{W}$ is a contiguity-based spatial weight matrix. A contiguity-based weight matrix was selected because state politicians tend to compare their own state policy those states with which they share a border. The contiguity based weight matrix also provides comparable weighting of neighbors across the United States, such that states in the northeast do not have substantially more neighbors than states in the western part of the country, as would happen in a distance- 
based weighting framework. Implementing the spatial autoregressive component yields the SDM model,

$$
\begin{gathered}
\text { TCS }_{\mathrm{it}}=\text { } \text { WTCS }_{\mathrm{it}}+\text { PRODUCER }_{\mathrm{it}} \beta+\text { IDEOLOGY }_{\mathrm{it}}^{\prime} \gamma+\mathrm{X}_{\mathrm{it}}^{\prime} \delta+ \\
\mathrm{W}\left[\text { PRODUCER }_{\mathrm{it}}^{\prime} \theta+\text { IDEOLOGY }_{\mathrm{it}}^{\prime} \psi+\mathrm{X}_{\mathrm{it}}^{\prime} \sigma\right]+\varepsilon_{\mathrm{it}},
\end{gathered}
$$

which can be econometrically estimated using maximum likelihood, therefore eliminating the natural endogeneity occurring from including a spatial dependent variable component, in the form

$$
\begin{gathered}
\text { TCS }_{\mathrm{it}}=\mathrm{A}\left\{\text { PRODUCER' }_{\mathrm{it}}^{\prime} \beta+\text { IDEOLOGY }_{\mathrm{it}}^{\prime} \gamma+\mathrm{X}_{\mathrm{it}}^{\prime} \delta+\right. \\
\left.\mathrm{W}\left[\text { PRODUCER }_{\mathrm{it}} \theta+\text { IDEOLOGY }_{\mathrm{it}}^{\prime} \psi+\mathrm{X}_{\mathrm{it}}^{\prime} \sigma\right]+\varepsilon_{\mathrm{it}}\right\} \text {, where } \mathrm{A}=\left(\mathrm{I}_{\mathrm{N}}-\rho \mathrm{W}\right)^{-1}
\end{gathered}
$$

and $\rho$ is an endogenous scalar that estimates the magnitude of spatial interaction (or 'locational similarity'). This matrix considers state neighbors to account for 'neighborhood' effects in tobacco control spending. The results are presented in Table 19. The coefficients on the nonspatially-weighted variables represent the direct effects, similar to the interpretation of the [beta coefficients of the OLS], while the spatially-weighted variables represent the indirect (spillover) effects. The total effect can be calculated at the sum of the direct and indirect effects.

Columns one and two present the results from the SDM. The $\rho$ parameter was positive, suggesting that states set TCF funding levels per capita similar to their neighbors, but the coefficient was not statistically significant. With a non-significant $\rho$, it is not surprising that the results from the SLX are extremely similar to the results of the SAR and that a majority of the indirect (spillover) effects are likewise insignificant.

The spatially-weighted special interest measure was negative, but not statistically significant, so the OLS model does not substantially underestimate the total effect of special interest groups like the models presented in Chapter 2. Curiously, the more revenue that a state's 
neighbors received from the MSA led to lower TCF levels. The resulting conclusion from the spatial analysis is that states are not competitive over TCF levels. Because of rigid competition over other areas of state policies, such as favorable tax rates, states shifted their fungible MSA revenue to other programs. So, as a state's neighbors collected more fungible revenue from the MSA, that state had to spend less on TCF to stay competitive in other areas.

\subsection{CONCLUSION}

This paper puts forth an empirical political economy framework for thinking about crossstate variation in TCF. We find that the special interest group effect partially explains why some states spend so comparatively little on tobacco control. These results have strong implications for organizations which seek to promote public health through tobacco cessation programs and policies oriented around controlling the use of tobacco among adolescents. Specifically, these organizations must contend with the pull of strong political incentives which emanate from tobacco lobbies and other sources of political influence which misalign the incentives faced by political actors with broader public health goals. 
Figure 4 State Tobacco Control Spending (2007 Dollars Per Capita) and State Tobacco Production (Pounds of Tobacco) in 2007, Respectively
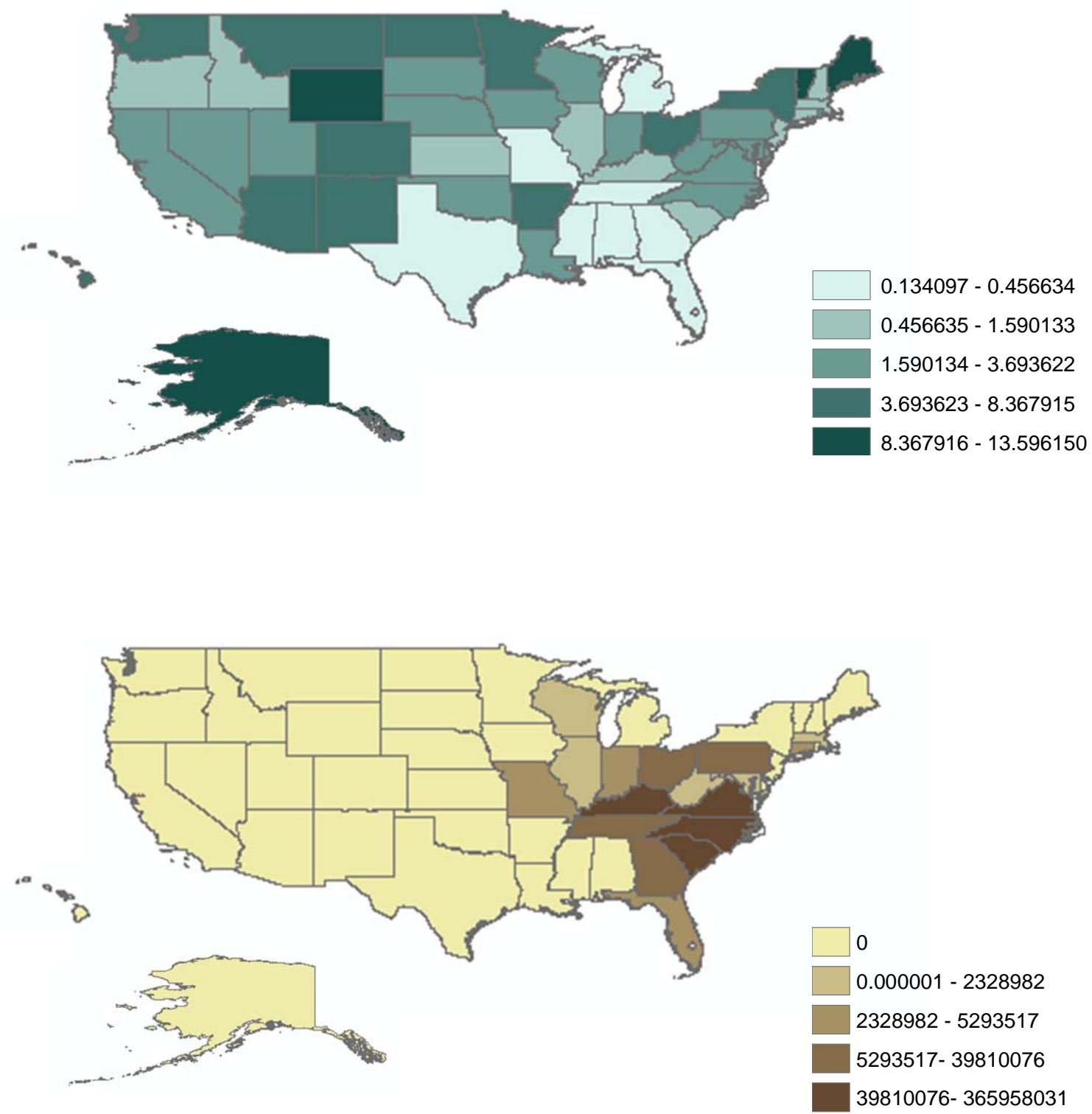
Table 14 Data and Summary Statistics

\begin{tabular}{|c|c|c|c|c|c|}
\hline & Source & Mean & Std. Dev. & Min & Max \\
\hline $\begin{array}{l}\text { Tobacco Control Funding } \\
\text { (RPC) }\end{array}$ & ImpacTeen Chartbook & 3.274 & 3.095 & 0.100 & 16.320 \\
\hline Tobacco Producer & Author Calculation & 0.436 & 0.497 & 0.000 & 1.000 \\
\hline Tobacco Tax Revenue (RPC) & ImpacTeen Chartbook & 41.419 & 27.712 & 2.270 & 150.080 \\
\hline $\begin{array}{l}\text { State Lobbying Expenditures } \\
\text { (Real, Thousands of Dollars) }\end{array}$ & $\begin{array}{l}\text { Center for Responsive } \\
\text { Politics }\end{array}$ & 1198.550 & 6402.870 & 0.000 & 67600.000 \\
\hline MSA Revenue (RPC) & ImpacTeen Chartbook & 27.447 & 11.257 & 0.000 & 80.910 \\
\hline Politician Ideology & Berry et al. (2010) & 49.289 & 27.715 & 0.000 & 97.500 \\
\hline Citizen Ideology & Berry et al. (1998) & 51.700 & 16.419 & 8.450 & 95.972 \\
\hline Beer Tax & Brewer’s Almanac 2008 & 24.996 & 19.962 & 2.000 & 107.000 \\
\hline $\begin{array}{l}\text { Tobacco Production } \\
\text { (Millions of Pounds) }\end{array}$ & USDA Agriculture Census & 17.706 & 63.258 & 0.000 & 490.416 \\
\hline Sales Tax & Tax Foundation & 4.747 & 1.840 & 0.000 & 7.250 \\
\hline Under 15 (Percent) & U.S. Census Bureau & 20.661 & 1.661 & 16.100 & 26.700 \\
\hline Over 65 (Percent) & U.S. Census Bureau & 12.615 & 1.797 & 5.510 & 17.718 \\
\hline Urban (Percent) & U.S. Census Bureau & 72.563 & 15.339 & 36.767 & 100.000 \\
\hline Education (Percent) & U.S. Census Bureau & 25.620 & 5.162 & 14.832 & 47.500 \\
\hline Debt Interest Payments (RPC) & U.S. Census Bureau & 0.169 & 0.229 & 0.008 & 2.402 \\
\hline Health Spending (RPC) & Tax Foundation & 0.382 & 0.606 & 0.009 & 6.908 \\
\hline Total Spending (RPC) & Tax Foundation & 6.135 & 9.600 & 0.410 & 130.934 \\
\hline GSP (RPC, in thousands) & BEA & 40.330 & 15.146 & 22.904 & 157.470 \\
\hline
\end{tabular}

Note: There are 408 observations for each variable (50 states plus D.C. over 8 years) and RPC is an acronym for real, per capita. 
Table 15 OLS Results for Tobacco Production

\begin{tabular}{lllll}
\hline & $\begin{array}{l}\text { Effects } \\
\text { Estimates }\end{array}$ & T-stat & $\begin{array}{l}\text { Effects } \\
\text { Estimates }\end{array}$ & T-stat \\
\hline Tobacco Production & -0.008 & $-3.738^{* * *}$ & -0.007 & $-3.288^{* * *}$ \\
Tobacco Revenue & 0.014 & $2.258^{* *}$ & 0.019 & $2.972^{* * *}$ \\
Settlement Revenue & 0.046 & $3.927^{* * *}$ & 0.036 & $2.786^{* * *}$ \\
Politician Ideology & 0.004 & 0.788 & 0.004 & 0.801 \\
Citizen Ideology & 0.031 & $2.347^{* *}$ & 0.0300 & $2.255^{* *}$ \\
Beer Tax & 0.018 & $2.973^{* * *}$ & 0.019 & $3.137^{* * *}$ \\
Sales Tax & 0.088 & 1.252 & 0.094 & 1.361 \\
Under 15 & 0.161 & $3.411^{* * *}$ & 0.268 & $1.735^{*}$ \\
Over 65 & -0.139 & $-2.320^{* *}$ & -0.041 & -0.353 \\
Urban & -0.083 & $-7.804^{* * *}$ & -0.088 & $-7.920^{* * *}$ \\
Education & 0.049 & 1.329 & 0.061 & 1.594 \\
Debt Interest Payments & -0.173 & -0.131 & 0.060 & 0.046 \\
Health Expenditures & -0.538 & -0.736 & -0.558 & -0.773 \\
General State Spending & 0.000 & 1.064 & 0.000 & 1.047 \\
GDP Per Capita & 0.051 & $3.853^{* * *}$ & 0.058 & $4.100^{* * *}$ \\
\hline Year Fixed Effects & \multicolumn{5}{c}{ NO } & YES \\
\hline N & \multicolumn{3}{c}{0.3596} & 408 \\
R & & & 0.3992 \\
\hline
\end{tabular}

The dependent variable for all specifications is real state-level TCF per capita. The key explanatory variable is state-level tobacco production (in millions of pounds). ${ }^{* * *}$ indicates statistical significance at the $1 \%$ level while $* *$ and $*$ represent statistical significance at the $5 \%$ and $10 \%$ levels, respectively. 
Table 16 OLS Results for Tobacco Producer

\begin{tabular}{|c|c|c|c|c|}
\hline & $\begin{array}{l}\text { Effects } \\
\text { Estimates }\end{array}$ & T-stat & $\begin{array}{l}\text { Effects } \\
\text { Estimates }\end{array}$ & T-stat \\
\hline Tobacco Producer & -1.343 & $-5.277 * * *$ & -1.321 & $-5.080 * * *$ \\
\hline Tobacco Revenue & 0.011 & $1.858^{*}$ & 0.015 & $2.409 * *$ \\
\hline Settlement Revenue & 0.052 & $4.491 * * *$ & 0.042 & $3.376 * * *$ \\
\hline Politician Ideology & 0.003 & 0.539 & 0.003 & 0.568 \\
\hline Citizen Ideology & 0.029 & $2.261 * *$ & 0.027 & $2.093^{* *}$ \\
\hline Beer Tax & 0.017 & $2.858 * * *$ & 0.018 & $3.010 * * *$ \\
\hline Sales Tax & 0.136 & $1.941 *$ & 0.143 & $2.062 * *$ \\
\hline Under 15 & 0.118 & $2.522 * *$ & 0.178 & 1.166 \\
\hline Over 65 & -0.067 & -1.101 & -0.005 & -0.045 \\
\hline Urban & -0.074 & $-7.223 * * *$ & -0.078 & $-7.153 * * *$ \\
\hline Education & 0.050 & 1.372 & 0.057 & 1.515 \\
\hline Debt Interest Payments & 0.307 & 0.235 & 0.558 & 0.436 \\
\hline Health Expenditures & -0.582 & -0.8100 & -0.594 & -0.838 \\
\hline General State Spending & 0.000 & 0.848 & 0.000 & 0.777 \\
\hline GDP Per Capita & 0.044 & $3.364 * * *$ & 0.049 & $3.508 * * *$ \\
\hline Year Fixed Effects & \multicolumn{2}{|c|}{ NO } & \multicolumn{2}{|c|}{ YES } \\
\hline $\mathrm{N}$ & \multicolumn{2}{|c|}{408} & \multicolumn{2}{|c|}{408} \\
\hline $\mathrm{R}^{2}$ & \multicolumn{2}{|c|}{0.381} & \multicolumn{2}{|c|}{0.421} \\
\hline
\end{tabular}

The dependent variable for all specifications is real state-level TCF per capita. The key explanatory variable is whether a state is a tobacco producer. $* * *$ indicates statistical significance at the $1 \%$ level while $* *$ and $*$ represent statistical significance at the $5 \%$ and $10 \%$ levels, respectively. 
Table 17 OLS Results for State Lobbying Expenditures

\begin{tabular}{lllll}
\hline & $\begin{array}{l}\text { Effects } \\
\text { Estimates }\end{array}$ & T-stat & $\begin{array}{l}\text { Effects } \\
\text { Estimates }\end{array}$ & T-stat \\
\hline Tobacco Lobby & -0.041 & $-2.089^{* *}$ & -0.039 & $-1.995^{* *}$ \\
Tobacco Revenue & 0.018 & $2.824^{* * *}$ & 0.022 & $3.496^{* * *}$ \\
Settlement Revenue & 0.049 & $4.122^{* * *}$ & 0.038 & $2.937^{* * *}$ \\
Politician Ideology & 0.002 & 0.351 & 0.003 & 0.570 \\
Citizen Ideology & 0.035 & $2.620^{* * *}$ & 0.035 & $2.644^{* * *}$ \\
Beer Tax & 0.017 & $2.785^{* * *}$ & 0.018 & $3.030^{* * *}$ \\
Sales Tax & 0.062 & 0.879 & 0.068 & 0.980 \\
Under 15 & 0.155 & $3.269^{* * *}$ & 0.373 & $2.483^{* *}$ \\
Over 65 & -0.158 & $-2.637^{* * *}$ & 0.019 & 0.160 \\
Urban & -0.079 & $-7.387^{* * *}$ & -0.087 & $-7.787^{* * *}$ \\
Education & 0.049 & 1.317 & 0.070 & $1.819^{*}$ \\
Debt Interest Payments & -0.272 & -0.203 & -0.024 & -0.018 \\
Health Expenditures & -0.410 & -0.554 & -0.504 & -0.692 \\
General State Spending & 0.000 & 0.952 & 0.000 & 1.018 \\
GDP Per Capita & 0.047 & $3.477^{* * *}$ & 0.058 & $4.081^{* * *}$ \\
\hline Year Fixed Effects & \multicolumn{5}{c}{ NO } & YES \\
\hline N & \multicolumn{3}{c}{0.344} & 408 \\
$\mathrm{R}^{2}$ & & & 0.389 \\
\hline
\end{tabular}

The dependent variable for all specifications is real state-level TCF per capita. The key explanatory variable is the level of state legislative campaign contributions from tobacco lobbies. *** indicates statistical significance at the $1 \%$ level while ** and * represent statistical significance at the $5 \%$ and $10 \%$ levels, respectively. 
Table 18 Model Specification Results

\begin{tabular}{llc}
\hline Model & OLS & SLX \\
\hline LM Lag & $9.168^{* * *}$ & 1.445 \\
LM Error & $11.624^{* * *}$ & 1.523 \\
LM Lag Robust & 0.056 & 0.000 \\
LM Error Robust & 0.065 & 0.000 \\
\hline
\end{tabular}


Table 19 Spatial Econometric Results for Tobacco Production

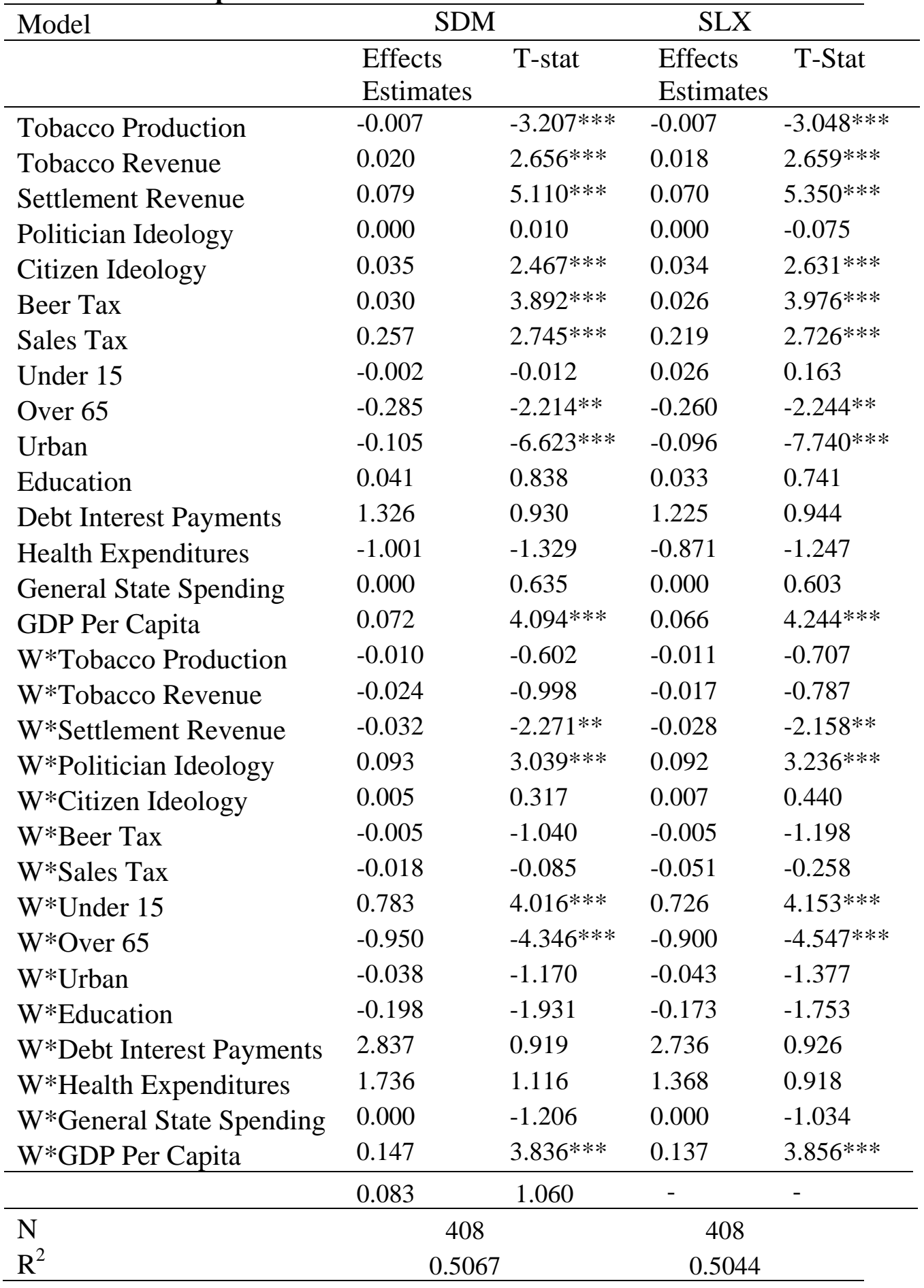

The dependent variable for all specifications is real state-level TCF per capita.

*** indicates statistical significance at the $1 \%$ level while ** and * represent statistical significance at the $5 \%$ and $10 \%$ levels, respectively. Statistical significance determined by z-probability. 


\section{References}

Anselin, Luc, Anil K. Bera, Raymond J. Florax, and Mann J. Yoon. 1996. Simple Diagnostic Tests for Spatial Dependence. Regional Science and Urban Economics, 26: 77-104.

Andrews, Rick, and George Franke. 1991. The Determinants of Cigarette Consumption: A Meta-Analysis. Journal of Public Policy \& Marketing 10, 3: 81-100.

Becker, Gary S. 1983. A Theory of Competition among Pressure Groups for Political Influence. Quarterly Journal of Economics, 98: 371-400.

Becker, Gary S., and Kevin M. Murphy. 1988. A Theory of Rational Addiction. Journal of Political Economy, 96, 4: 675.

Becker, Gary, Michael Grossman, and Kevin Murphy. 1994. An Empirical Analysis of Cigarette Addiction. The American Economic Review, 84, 3: 396-418.

Berry, William D., Richard C. Fording, Evan J. Ringquist, Russell L. Hanson and Carl Klarner. 2010. Measuring Citizen and Government Ideology in the American States: A Re-appraisal. State Politics and Policy Quarterly. 10: 117-35.

Berry, William D., Evan J. Ringquist, Richard C. Fording and Russell L. Hanson. 1998. Measuring Citizen and Government Ideology in the American States, 1960-93. American Journal of Political Science. 42: 327-48.

Besley, Timothy J, and Harvey S. Rosen. 1998. Vertical Externalities in Tax Setting: Evidence from Gasoline and Cigarettes. Journal of Public Economics, 70: 383-98.

Brulhart, Marius, and Mario Jametti. 2008. Does Tax Competition Tame Leviathan?. Working Paper.

. 2006. Vertical Versus Horizontal Tax Externalities: An Empirical Test. Journal of Public Economics. 90: 2027-2062.

Chaloupka, Frank. Rational Addictive Behavior and Cigarette Smoking. The Journal of Political Economy 99, 4: 722-742.

Chib, S. and B.P. Carlin. 1999. On MCMC sampling in hierarchical longitudinal models. Statistics and Computing, 9: 17-26.

Debarsy, N., Ertur, C., \& LeSage, J. 2011. Interpreting Dynamic Space-Time Panel Data Models. Statistical Methodology, 1-14. 
Devereux, Michael, Ben. Lockwood, and Michela Redoano. 2007. Horizontal and vertical indirect tax competition: Theory and some evidence from the USA. Journal of Public Economics. 91: 451-479.

Ekelund, Robert B. and Robert D. Tollison. 2001. The Interest Group Theory of Government. In William F. Shughart II and Laura Razzolini (eds.), The Elgar Companion to Public Choice, Vol. 1. Cheltenham, U.K.: Edward Elgar Publishers, pp. 357-378.

Emery, S. M. M. White, E. A. Gilpin, and J. P. Pierce. 2002. Was There Significant Tax Evasion After the 199950 Cent Tax Increase in California? Tobacco Control. 11: 130-134.

Elhorst, J.P. 2009. Spatial Panel Data Models. In Fisher MM, A Getis (eds.), Handbook of Applied Spatial Analysis, Ch. 2. Springer: Berline Heidelberg, New York.

Fredriksson, Per G., and Khawaja A. Mamun. 2008. Vertical externalities in cigarette taxation: Do Revenues go up in smoke?. Journal of Urban Economics 64: 35-48.

Farrelly, Matthem, Christian Nimsch, and Joshua James. 2003. State Cigarette Excise Taxes: Implications for Revenue and Tax Evasion. Report prepared for the Tobacco Technical Assistance Consortium.

Farrelly, Matthew C., Terry F. Pechacek, and Frank J. Chaloupka. 2003. Journal of Health Economics, 22(5): 843-859.

Florax, Raymond, Hendrik Folmer, and Sergio Rey. 2003. Specification Searches in Spatial Econometrics: The Relevance of Hendry's Methodology. Regional Science and Urban Economics, 33: 557-79.

Fox, William, F., Brian C. Hill, and Matthew N. Murray. 2011. Vertical Competition, Horizontal Competition and Mobile Capital: An Empirical Investigation. Working Paper.

Gallet, Craig, and John List. 2002. Cigarette Demand: A Meta-Analysis of Elasticities. Health Economics 835: 821-835.

Garrett, Thomas A., and Thomas L. Marsh. 2002. The revenue impact of cross-border lottery shopping in the presence of spatial autocorrelation. Regional Science and Urban Economics 32 (4): 501-1

Giovino, Gary A., Frank J. Chaloupka, Anne M. Hartman et al. 2009. Cigarette Smoking Prevalence and Policies in the 50 States: An Era of Change - The Robert Wood Johnson Foundation ImpacTeen Tobacco Chart Book. Buffalo, NY: University at Buffalo, State University of New York. 
Gruber, Jonathan, and Botond Koszegi. 2001. Is Addiction "Rational"? Theory and Evidence. The Quarterly Journal of Economics 116, 4: 1261-1303.

. 2002. A Theory of Government Regulation of Addictive Bads: Optimal Tax Levels and Tax Incidence For Cigarette Excise Taxation. NBER working paper. . 2004. Tax Incidence When Individuals Are Time-Inconsistent: The Case of Cigarette Excise Taxes. Journal of Public Economics, 88: 1959 - 1987.

Hoffer, Adam. 2011. Spatial Dependence in Tobacco Excise Taxation: An Analysis of Special Interest and Tax Competition. Working paper.

Hoffer, Adam and Adam Pellillo (In Press). The Political Economy of Tobacco Control Spending. Applied Economics Letters.

Holcombe, Randall. 1997. Selective Excise Taxation from an Interest-Group Perspective. In William Shughart II (Ed.), Taxing Choice: The Predatory Politics of Fiscal Discrimination, New Brunswick. Transaction Publishers. pp. 81-103.

Holcombe, Randall G. 1998. Tax Policy From a Public Choice Perspective. National Tax Journal. 51(2): 351-379.

Hu, T. W., H. Y. Sung, and T. E. Keeler. 1995. The State Antismoking Campaign and the Industry Response: The Effects of Advertising on Cigarette Consumption in California, American Economic Review. 85(2): 85-90.

Kanbur, Ravi. and Michael. Keen. 1993. Jeux sans frontiers: tax competition and tax coordination when countries differ in size. American Economic Review. 83: 887-892.

Keen, Michael. 1998. Vertical tax externalities in the theory of fiscal federalism. IMF Staff Papers. 45: 454-485.

Koop, G. 2003. Bayesian Econometrics, John Wiley \& Sons, West Sussex, England.

Kreuger, Anne O. 1974. The Political Economy of a Rent-Seeking Society, American Economic Review, 64, pp. 291-303.

LeSage, James P., and Matthew Dominguez. 2010. The Importance of Modeling Spatial Spillovers in Public Choice Analysis. Public Choice. 146: 1-21.

LeSage, James P., and R Kelley Pace. 2009. Introduction to Spatial Econometrics. Boca Raton: CRC Press/Taylor \& Francis.

Marlow, Michael. 2009. Is the CDC Blowing Smoke?. Regulation, 32(2): 46-52. 
Merriman, David. 1994. Do Cigarette Excise Tax Rates Maximize Revenue?. Economic Inquiry, 32, 3: 419.

Nelsen, Michael. 2002. Using Excise Taxes to Finance State Government: Do Neighboring State Taxation Policy and Cross-Border Markets Matter?. Journal of Regional Science, 42, 4: 731-752.

Nielson, Soren B. 2001. A simple model of commodity taxation and cross-border shopping. Scandinavial Journal of Economics, 103: 599-623.

Orzechowski, W, and R Walker. 2007. The Tax Burden on Tobacco. Historical Compilation 42.

Pearce, Bob, Andy Bailey, Kenny Seebold, and Lee Townsend. 2011. Field Selection, Tillage, and Fertilization. In Kenny Seebold and Bob Pearce (Eds.), 2011-2012 Kentucky \& Tennessee Tobacco Production Guide. pp. 13-24.

Pearce, Bob, Paul Denton, and Greg Schwab. 2011. Management of Tobacco Float Systems. In Kenny Seebold and Bob Pearce (Eds.), 2011-2012 Kentucky \& Tennessee Tobacco Production Guide. pp. 24-29.

Peltzman, Sam. 1976. Toward a More General Theory of Regulation. Journal of Law and Economics, 19(2): 211-48.

Rizzo, Leonzio. 2010. Interaction Between Federal Taxation and Horizontal Tax Competition: Theory and Evidence from Canada. Public Choice. 144: 369-387.

Rork, John C. 2003. Coveting They Neighbor's Taxation. National Tax Journal. 57: 775787.

Shipan, Charles R, and Craig Volden. 2006. Bottom-Up Federalism: The Diffusion of Antismoking Policies from U.S. Cities to States. American Journal of Political Science 50(4): 825-843.

2008. The Mechanisms of Policy Diffusion. American Journal of Political Science 52(4): 840-857.

Skidmore, Mark and Mehmet Serkan Tosun. 2008. Do New Lottery Games Stimulate Retail Activity? Evidence from West Virginia Counties. The Journal of Regional Analysis \& Policy, 38(2): 45-55.

Sloan, Frank A., Jan Ostermann, Gabriel Picone, Christopher Conover, and David H. Taylor Jr. 2004. The Price of Smoking. Cambridge. MIT Press.

Stigler, George J. 1971. The Theory of Economic Regulation. Bell Journal of Economics and Management Science, 2(1): 3-21. 
Tauras, John A. 2005. State Tobacco Control Spending and Youth Smoking, American Journal of Public Health, Volume 95.

Tullock, Gordon. 1967. The Welfare Cost of Tariffs, Monopolies, and Theft, Western Economic Journal, 5, 3, pp. 224-232.

Viscusi, Kip W. 1994. Cigarette Taxation and the Social Consequences of Smoking, in: Poterba, James M. (Ed.), Tax Policy and the Economy, Volume 9. MIT Press. pp. 51102.

Wakefield, Melanie and Frank Chaloupka. 2000. Effectiveness of comprehensive tobacco control programmes in reducing teenage smoking in the USA. Tobacco Control. 9:177-186. 